\title{
EXPLORATION OF THE UNIQUE FIRM RESOURCES DESCRIBED BY INDIAN APPAREL EXPORT FIRMS FOR THEIR COMPETITIVE ADVANTAGES
}

A Thesis
Presented to
The Faculty of the Graduate School
At the University of Missouri
In Partial Fulfillment
Of the Requirements for the Degree
Master of Science
BEBANJAN DAS
Dr. Jung Ha-Brookshire, Thesis Supervisor

July 2013 
The undersigned, appointed by the dean of the Graduate School, have examined the Thesis entitled

\section{EXPLORATION OF THE UNIQUE FIRM RESOURCES DESCRIBED BY INDIAN APPAREL EXPORT FIRMS FOR THEIR COMPETITIVE ADVANTAGES}

Presented by Debanjan Das

A candidate for the degree of

Master of Science

And hereby certify that, in their opinion, it is worthy of acceptance.

Dr. Jung Ha-Brookshire

Dr. Jana Hawley

Dr. Yong Volz 
To my family, for always believing in me. 


\section{ACKNOWLeDgements}

Foremost, I would like to express my sincere gratitude to my advisor Dr. HaBrookshire for the continuous guidance, support, and motivation. Her guidance helped me in all the time of research and writing of this thesis. I could not have imagined having a better advisor and mentor. I would also like to thank Dr. Hawley for constant encouragement, insightful comments, and hard questions and also helping me in understanding the Indian textile and apparel industry from a global perspective.

Furthermore I would like to thank Dr. Volz for introducing me to the fantastic world of qualitative research. She has taught me to think beyond the numbers and made me believe that words are more valuable than numbers. Also, I would like to thank the participants in my study, who have willingly shared their precious time during the process of interviewing. 


\section{CONTENTS}

ACKNOWLEDGEMENTS ....................................................................... II

LiST OF FIGURES....................................................................... V

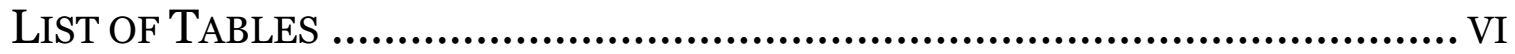

LIST OF APPENDIXES .................................................................. VII

ABSTRACT …............................................................................. VIII

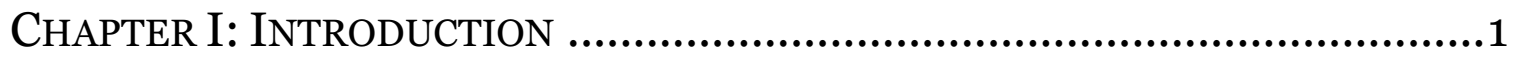

Background of the study ................................................................................ 1

Purpose of the study ..................................................................................... 3

Significance of the study .................................................................................. 3

CHAPTER II: LITERATURE REVIEW ..................................................... 6

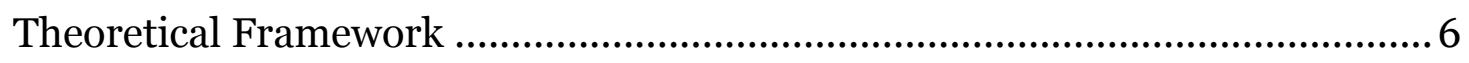

Porter's theory of competitive advantage of nations ....................................... 6

Resource-based theory of the firm............................................................... 10

Indian Apparel Export Industry ......................................................14

Historical Perspective ................................................................................... 14

Current Indian Apparel Export industry ……………................................... 16

Summary of research gaps and questions ..................................................... 25

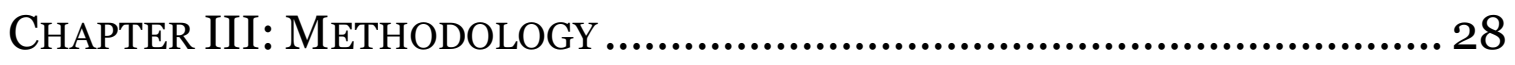

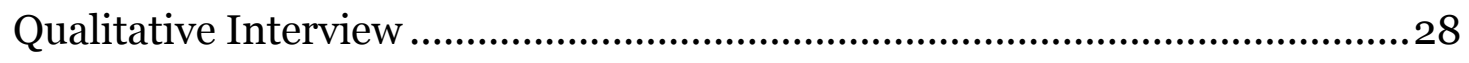

Sample

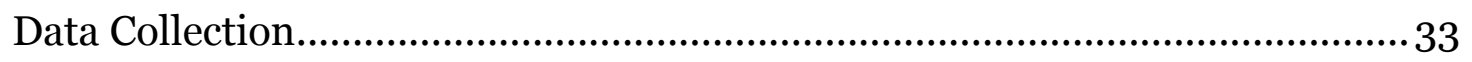

Validation Strategies...................................................................................... 36

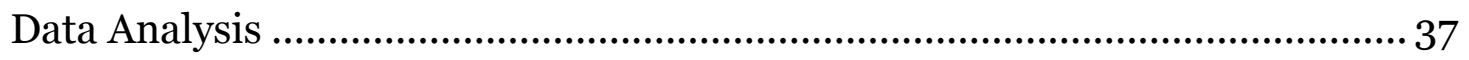


CHAPTER IV: RESULTS ……………...................................... 38

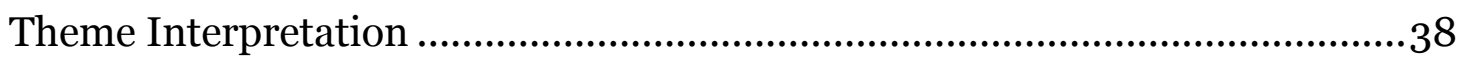

Key Competitive Advantages .....................................................................38

Key Resources of the Indian Apparel Export Firms .......................................4 43

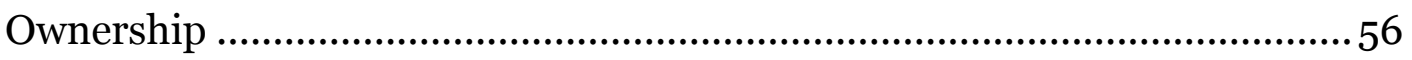

Demand Conditions ..................................................................................... 59

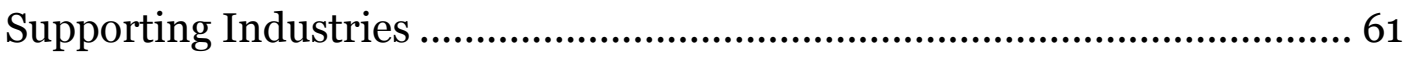

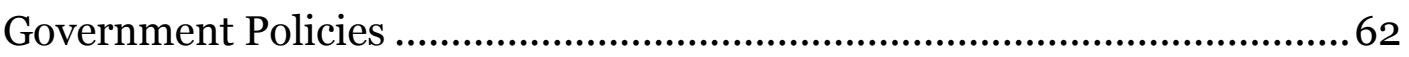

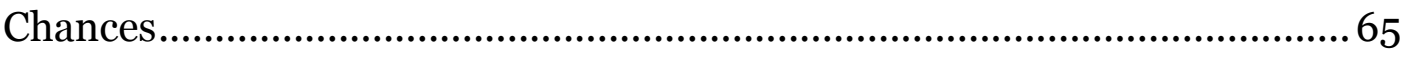

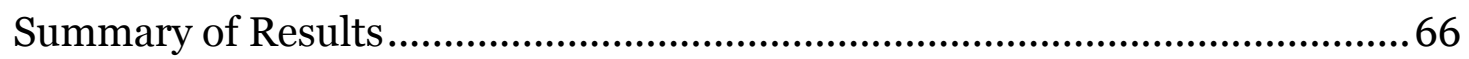

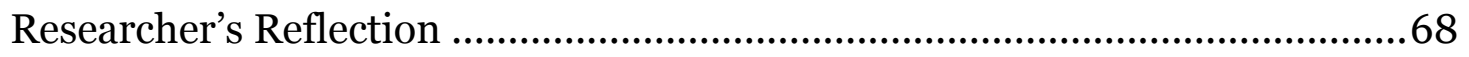

CHAPTER V: CONCLUSIONS ........................................................... 70

Summary of the study ..........................................................................................70

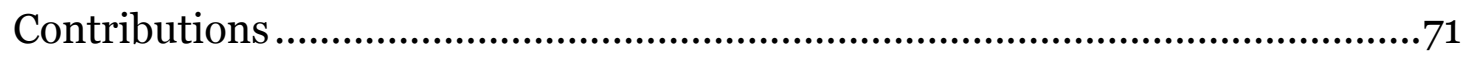

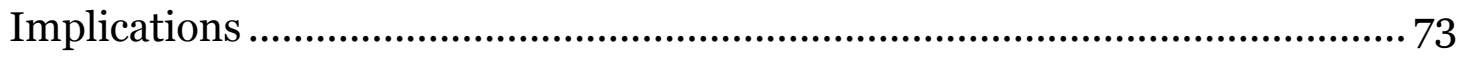

Limitations and Future Research Opportunities ................................................ 75

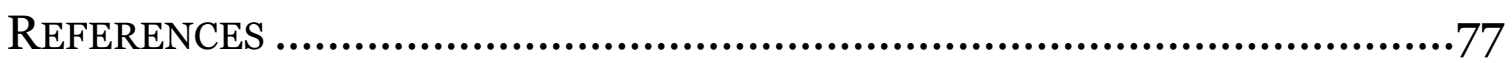

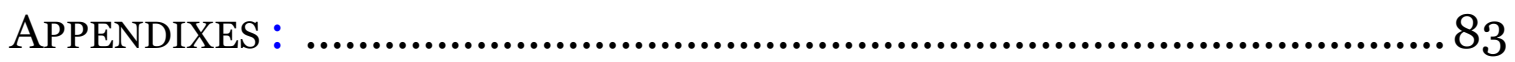

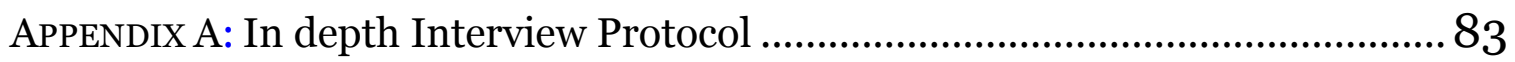

APPENDIX B: Revised In depth Interview after Pilot Run .................................... 87

APPENDIX C:Email Recruitment ..........................................................................

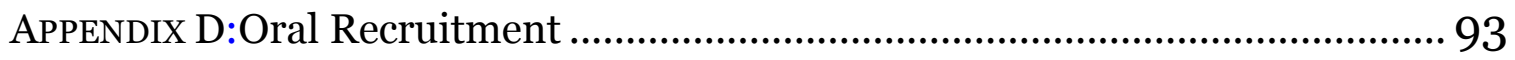

APPENDIX E: Study Consent Form …………………....................................... 95

APPENDIX F: Study Consent Form (in Hindi) ...................................................... 98

APPENDIX G: Study Consent Form (in Tamil) …………………………….......100

APPENDIX H: Study Consent Form (in Kannada).................................................. 104

APPENDIX I: Institutional Review Board Approval for Final................................. 107 


\section{LIST OF FigURES}

Figure 1: Porter's Diamond Model ................................................................. 710

Figure 2: Map of India with Major Apparel Clusters ............................................. 16

Figure 3: The Study Framework pertaining to Indian Apparel Export Firms ...... 27

Figure 4: Summary of the Results pertaining to Indian Apparel Export Firms ... 67 


\section{LIST OF TABLES}

Table 1: Demographic Characteristics of Participants ..........................................30

Table 2: Demographic Characteristics of Indian Apparel Export Firms ...............32 


\section{LIST OF APPENDIXES}

APPENDIX A: In depth Interview Protocol .......................................................... 83

APPENDIX B: Revised In depth Interview after Pilot Run ..................................... 87

APPENDIX C:Email Recruitment ……………………........................................ 91

APPENDIX D:Oral Recruitment ............................................................................ 93

APPENDIX E: Study Consent Form ............................................................................. 95

APPENDIX F: Study Consent Form (in Hindi) ......................................................98

APPENDIX G: Study Consent Form (in Tamil) ………….....................................100

APPENDIX H: Study Consent Form (in Kannada).................................................. 104

APPENDIX I: Institutional Review Board Approval for Final................................. 107 


\begin{abstract}
The study explored the key competitive advantages and resources of the Indian apparel export firms. According to Porter's (1990) theory of competitive advantage of nations, a nation succeeds in a particular industry if it possesses a competitive advantage relative to the best worldwide competitors. In addition, the resource based theory of the firm defines competitive advantage as a value creating strategy being implemented by a firm while other potential competitors do not or cannot (Barney, 1991). These theories formed the theoretical background of the study. The interpretation from a qualitative study approach, which used semi-structured interviews and field observations of eighteen top level executives working in the apparel export industry in Tirupur and Bangalore revealed four competitive advantages: (a) product advantage; (b) price advantage; (c) delivery advantage and; (c) service advantage. Implications derived from the results offer several important opportunities. Through an in-depth understanding of the key resources of the Indian apparel export firms, the findings help the Indian apparel export firms in realizing their actual key resources and competitive advantages. Government policy makers may want to utilize the study findings to develop more flexible and effective policies that may be more fruitful in the long term.
\end{abstract}

Keywords: India, apparel export industry, firm resource, competitive advantages 


\section{CHAPTER I: INTRODUCTION}

Chapter I contains the following sections: (a) background of the study, (b) purpose of the study, and (c) significance of the study.

\section{Background of the study}

The Indian apparel industry has been in a growing phase since the late 1980s.

Presently, India is the sixth largest apparel exporter in the world, with exporting to U.S. $\$ 14.5$ billion worth of apparel (World Trade Organization, 2012). However, recently, the growth of the Indian apparel export firms has slowed dramatically. The slow growth rate has affected the Indian apparel export firms and they might be reevaluating their key firm resources and their competitive advantages to sustain themselves (Kathuria, 2008). Stiff competition from neighboring developing countries may be one of the reasons for the low growth in international market shares.

Among the neighboring competitive countries, China has been a dominant player in apparel export in the global market-place since the abolition of the quota system in 2005 (Tewari, 2006). The ability to provide a large quantity of quality products at low cost has made China the most favorable sourcing destination in the past few decades. However, an increase in labor wages, rise in commodity prices, rising transportation and logistics costs, and appreciation of Yuan (Chinese currency) has also negatively affected China's position as the cheapest sourcing destination. Chang and Ha-Brookshire (2011) found that the Chinese apparel industry seems to be in the mature stage and Chinese apparel firms are now emphasizing the development of their own brands and domestic retailing, rather than exporting. China exported U.S. \$153.8 billion worth of apparel in 
2011. In comparison, Hong Kong exported $\$ 24.5$ billion, Bangladesh exported $\$ 19.9$ billion and India exported $\$ 14.5$ billion worth of apparel (World Trade Organization, 2011).

As China is moving its focus from export to brand development and retailing, India has been considered one of the next sourcing destinations that might replace China, due to its abundant skilled labor force, low labor wages, and flexible manufacturing infrastructure (Das \& Ha-Brookshire, in review). However, experts say the growth of exports in India has failed to meet its expectation (Kathuria, 2008). For example, there was only $0.28 \%$ increase in Indian apparel exports from 2010 to 2011, while Bangladesh apparel exports increased by $0.38 \%$ during the same period (World Trade Organization, 2011). That is, Bangladesh seems to be more effectively taking advantage of the decrease in Chinese production than India. Kathuria (2008) found that Indian labor wage was comparatively higher than that of Bangladesh, and the productivity of Indian human resources was comparatively lower than Bangladesh labors. Thus, Kathuria tried to explain why India could not meet its expected export growth. Lu \& Karpova (2011) found that fragmented manufacturing facilities, unreliable transportation and logistics services, low managerial flexibility and adaptability, and low labor productivity were the main reasons behind India's slow apparel export growth rate.

Although these studies showed interesting reasons for India's slow growth, no research studied what the Indian apparel export firms consider as their key resources at the micro level. What do Indian apparel exporters have to compete against global competitors? What do the Indian apparel export firms have, in terms of unique firm resources to compete against any other countries for that matter or China, in order to 
increase their share in the global apparel market-place? How do major market forces affect and shape Indian apparel exporters' key firm resources? How do such resources help establish and sustain their competitive advantages? This study is designed to find the unique key firm resources that help the export firms in sustaining competitive advantage and identify the factors that help the firms in developing, maintaining and acquiring these key firm resources.

\section{Purpose of the study}

The purpose of the study is to gain a deep understanding of the actual firm resources possessed by the Indian apparel export firms. More specifically, the study aims to understand how do (a) ownership types, (b) foreign buyer demand conditions, (c) apparel-related industries, such as textile and dyeing industries, (d) government export promotion policies, and (e) changes, such as current economic conditions or recession, shape and influence the development and maintenance of companies' key resources. This will be achieved through the theoretical frameworks of Barney's Resource based Theory and Porter's Diamond model of the National Competitive Advantage.

\section{Significance of the study}

Today, India is considered as one of the fastest growing economies in the world. The apparel export sector contributes hugely to this rapid economic growth. The apparel industry contributes approximately $14 \%$ to Indian industrial production, $4 \%$ to the Gross Domestic Products (GDP), and 17\% to the country's export earnings (Ministry of Textiles, 2012). The apparel industry is one of India's largest revenue generators, in terms of GDP, exports, and employment (AEPC, 2012). Exploring the Indian apparel export firms key resources and the factors influencing in shaping and developing these 
firm resources has several significant aspects to the Indian apparel industry, practitioners and to academia.

First, the findings will provide an understanding of the important key firm resources unique to Indian apparel export firms and will provide insights into the different factors influencing the development and maintenance of these unique key firm resources. These insights will provide a comparative picture of the Indian apparel export firms.

Second, by exploring the key resources of the Indian apparel export firms, the study findings may help prospective investors, who are interested in investing in the apparel export sector in India to prepare themselves with these key unique resources they must develop, obtain, and improve when they invest or start a new business in India.

Third, this study could contribute to the development of students in apparel academic units preparing for a future career in the apparel industry. Expected findings may help add to the existing curriculum to incorporate knowledge and skill sets to help the Indian apparel export industry achieve the unique key firm resources. This can assist in strengthening education for the future generation and assist them in selecting right job for them. Thus the study findings may be an important trend guide for educators and students in the apparel related programs in India to decide which skills and knowledge should be the program focus.

Finally, the study findings may enrich and add depth to the firms' resources literature especially from the perspective of Indian exports in the apparel industry. The results may be useful for human resource departments in constructing and developing realistic job profiles. Additionally, businesses may be able to use the study's findings to 
help structure a stronger career development programs to ensure job satisfaction, which would help recruit and retain talented employees. 


\section{CHAPTER II: LITERATURE REVIEW}

Chapter II contains the following sections: (a) Theoretical Frameworks, (b) Indian Apparel Industry, (c) research gap and questions

\section{Theoretical Framework}

\section{Porter's theory of competitive advantage of nations}

Michael Porter's theory of competitive advantage of nations (diamond model) provides an excellent framework to analyze the competitiveness of a particular industry within a country (Jin \& Moon, 2006). Porter's (1990) theory states that a nation succeeds in a particular industry if it possesses a competitive advantage relative to the best worldwide competitors. Porter also proposed that the characteristics of the national environment influence the competitive advantages of a nation and identifies four primary determinants that affect competitive performance of firms: factor conditions; demand conditions; related and supporting industries; and firm strategy, structure, and rivalry. These determinants interact with each other to form the nation's diamond, and interrelations between the determinants establish national competitiveness (Grant, 1991). 
Figure 1: Porter's Diamond Model

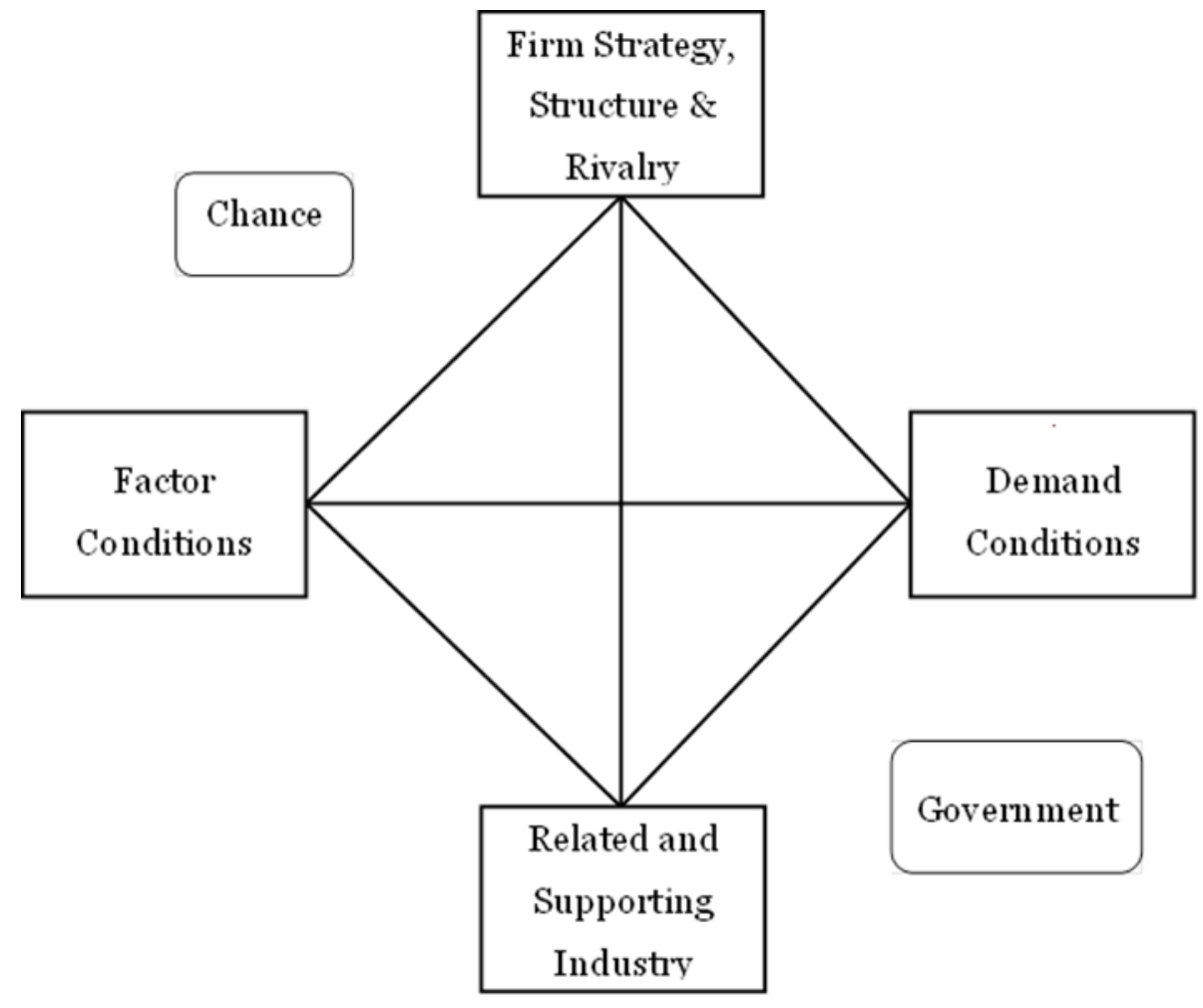

Source: Adopted from Porter (1998, p.127)

\section{Factor Conditions}

Factor conditions are defined as “the nation's position in factors of production, such as skilled labor or infrastructure, necessary to compete in a given industry" (Porter, 1990, p. 71). Porter categorizes factor conditions as basic factors or generalized factors and advanced factors or specialized factors. A basic factor is passively inherited, such as climate, unskilled and semiskilled labor and provides initial advantage, while advanced factors include conditions a nation creates, such as communication, infrastructure, sophisticated skills, and research facilities, are created through investment by individuals, companies and governments and play most critical roles for enhancing a nation's competitive advantage (Grant, 1991). Porter suggested that competitive advantage based 
on basic or generalized factors is unsophisticated and often fleeting, contending that advanced or specialized factors are necessary for more sophisticated forms of competitive advantages. Basic factors can be extended and reinforced through advanced factors and unfavorable basic factor conditions (e.g. excess or lack of raw material or labor) can create pressure to develop advanced factors, further making industries highly competitive.

\section{Demand conditions}

Demand conditions are defined as “the nature of home demand for the industry's product or service" (Porter, 1990, p. 71). Porter (1998) views demand conditions in terms of the size of the home market and sophisticated and demanding buyers. Porter acknowledges that the size of domestic demand in a particular industry may be important to national advantage where there are significant economies of scale or learning, but he considered the presence of sophisticated and demanding buyers more important. While sophisticated home demand forces firms towards better products and services, varying levels of sophistication in consumer demands lead to market segmentation.

\section{Related and supporting industries}

Related and supporting industries are defined as "the presence or absence in the nation of supplier industries and related industries that are internationally competitive" (Porter, 1990, p. 71). Porter relates this dimension to spillover benefits that go beyond the boundaries of an industry, to explain the tendency of successful firms within a country to form clusters of related and supporting industries (Grant, 1991). Porter (1998) asserted that the presence of supplier and related industries within a nation that are internationally competitive provides benefits such as innovation, upgrading, information flow, and 
shared technology development which create advantages in downstream industries. Porter also emphasizes the importance of forming clusters to deliver cost-effective inputs and highlights the importance of these supporting industries to innovate by working closely with the end-user.

\section{Firm strategy, structure, and rivalry}

Firm strategy, structure, and rivalry is defined as "the conditions in the nation governing how companies are created, organized, and managed, as well as the nature of domestic rivalry" (Porter, 1990, p. 71). Competitiveness is created by the convergence of favorable management practices and organizational models specific to that country (Porter, 1990). For example, the large number of family-owned companies in Italy has contributed to the success of fashion industries where responsiveness and flexibility are critical to gain competitive advantage (Grant, 1991). Porter also emphasizes that in addition to firm strategy and structure, rivalry plays a critical role in increasing competitive advantage by forcing firms to cut costs, improve quality and innovate (Grant, 1991).

In addition to these four determinants, Porter (1998) suggested two external determinants: chance and government. Chance events just happen; however, the nation with the most favorable "diamond" will most likely convert chance events into competitive advantage (Porter, 1998). The government can interact with the four determinants by fostering or deterring the development of a nation's competitive advantage.

Figure 1 shows the Porter's diamond model and provides a brief explanation of the theory of of competitive advantage of nations. The model explains a nation's success 
in a particular industry, by describing the four interrelated determinants needed to attain competitive advantage. These four determinants include: factor conditions; demand conditions; related supporting industries; and firm strategy, structure, and rivalry. These four interrelated factors constitute a firm's global competitiveness in a given industry. The model suggests that the government policies and startegies act as a catalyst for companies to aspire to higher levels of competitive performance. The model also suggests that chance may influence industries competitive performance.

\section{Resource-based theory of the firm}

In addition to Porter's diamond model, resource-based theory of the firm (RBT) suggests that firms' competitive advantages are highly dependent on critical firm resources that competitors may not be able to easily copy. Penrose (1959) initiated the development of the resource-based view of the firm, where he concluded that firms should be described as an administrative unit that links and coordinates activities of numerous groups and individuals, and as a bundle of productive resources. The Penrose' view gained substantial traction in the mid-1980s as Wernerfelt (1984) recognized that competition for resources among firms would have important implications for the ability of firms to gain advantages. Wernerfelt (1984) focused on the possibility that the differences in firm performance could be developed, in terms of the resources that a firm controls. Two years later, Barney (1986) introduced the concept of strategic resource factors that firms could acquire or develop to implement the superior market strategies in the marketplace. In this light, Dierickx \& Cool (1989) showed that the firm's strategic resources assist in generating economic profits. All of these discussions on firms and their strategic resources lead to Barney's (1991) resource-based theory of the firm. 
The RBT explains that firms gain and sustain competitive advantages by deploying valuable resources and capabilities that are rare, and not readily replicable (Barney, 1991). Firm resources are defined as the tangible and intangible assets that firms use to develop and implement their strategies. These firm resources must be valuable so that it can exploit opportunities and / or neutralize threats in a firm's environment. Firm resources must also be rare among the firm's current and potential competitors. Firm resources must be costly-to-copy so that the firm can maintain the competitive advantage.

The RBT researchers suggest that these firm resources are key factors for their competitive advantages. Competitive advantage is defined as a value creating strategy being implemented by a firm while other potential competitors do not or cannot (Barney, 1991). These competitive advantages provide the edge to the firm to its competitors in order to generate economic profits. The competitive advantage is considered sustainable when the competitors of the firm are unable to replicate the value creating strategy.

\section{Key firm resources for competitive advantages from $R B T$}

Then, what are the key resources firms must have for their competitive advantages? Barney (1991) identified the three key firm resources for competitive advantages: (1) physical capital resources, (2) human capital resources, and (3) organizational capital resources. Physical capital resources refer to the physical assets of the firm, such as geographic location, accessibility to raw material, machineries and equipment. Human capital resources refer to the manpower present in the firm, such as the workers and managers. Organizational Capital resources refer to the structure of the firm, such as the controlling and coordinating organizational systems. Following Barney, many researchers investigated key firm resources for successful manufacturing in many 
different industries (e.g. Collins \& Clark, 2003; Ravichandran \& Lertwongsatien, 2005;

Runyan, Huddleston, \& Swinney, 2007; Watchravesringkan, Karpova, Hodges, \& Copeland, 2010).

In the export setting, researchers suggested that exporting firms require different firm resources for their competitive advantages, compared to general firms. Cavusgil \& Zou, (1994) emphasized that exporting is a firm's strategic response to perform against intense domestic and international competition. Therefore, the strategic dimension of exporting firms is critical to assess their performance. Piercy, Kaleka, \& Katsikeas (1998) studied small- and medium-sized British manufacturing and exporting firms in all type of product categories and found the abilities to offer competitive pricing, to produce superior product quality, and to provide responsive services as key resources for their competitive advantages.

Most recently, after reviewing all key firm resources discussed in the export performance literature, Enz (2008) proposed the five key firm resource categories, using U.S. food exporting firms as study subjects: (1) financial resources, including all of the monetary resources from which a firm can draw; (2) physical resources, such as land, buildings, equipment, locations, and access to raw materials; (3) human resources, which pertains to the skills, background, and training of managers and employees, as well as the way they are organized; (4) organizational knowledge and learning, such as management flexibility, consumer satisfaction, delivery, and quality; and (5) general organizational resources, including the firm's reputation, brand names, patents, contracts, and relationships with external stakeholders. 
In the apparel export setting, it is difficult to isolate firm resource study findings specifically related to apparel as much of previous studies investigated both textile and apparel export firms. However, these findings still provide good insights into apparel export firms' competitive advantages. For example, McCann (2011) found the key firm resources of the Chinese textile and apparel export firms were found to be accessibility to diverse and high quality raw materials, efficient and effective transportation and logistics services, vertically integrated production facilities, and low manufacturing cost. In addition to these firm resources, Shamsuddoha, Ali, \& Ndubisi (2009) observed that governments' export promotion programs help export performance of the textile and apparel industries in Bangladesh. Similarly, export performance of textile and apparel firms in Croatia was benefited from its government's trade agreements, industrial policy, and efforts for economic stability (Bezić, Cerović, \& Galović, 2011).

Based on the assumption that textile and apparel export firms may require different key firm resources than general export firms, Chang \& Ha-Brookshire (2011) surveyed Chinese textile and apparel firms' company profiles, using Enz's framework. Overall, the authors found 18 key resources possessed by successful Chinese textile and apparel export firms. The firm resources were good relationships, high quality, equipment, skilled human resources, customer satisfaction, fashion trend knowledge, company size, reputation, brand, location, product breadth, land or building, managerial knowledge, awards, industry certificates, financial resources, employee training programs and quick delivery. Particularly, organizational knowledge and learning resources, such as high quality, customer satisfaction, fashion trend knowledge, product breadth, 
managerial knowledge, and quick delivery, were most frequently mentioned key

resources by Chinese textile and apparel export firms.

The resource based theory of the firm provides a complete picture of the key firm resources unique to the apparel industry. Barney (1991) provided the concept of the main resources that enable firms to implement strategies to achieve competitive advantages. Enz(2008) modified Barney’s firm resources into five categories of financial resources, physical resources, human resources, general organizational resources and organizational knowledge and learning resources. This study follows Enz's framework to understand the Indian apparel export firms' key resources.

\section{INDIAN APPAREL EXPORT INDUSTRY}

\section{Historical Perspective}

The Indian apparel industry gained its importance during the Colonial rule of the British Empire. The British rule imported textile and apparel into India and forced Indian people to consume their products. As the Indian textile and apparel industry was not developed and disorganized, they could not compete with the British products In 1915, during this period, in order to boycott foreign goods, Gandhi started the "Khadi" movement. This movement aimed at producing apparel using homespun traditional method with the objective of collaboration of masses in production rather than mass production by a few (Gonsalves, p.64, 2010). Gandhi used Khadi to motivate Indian people to fight against the British rule in a non-violent way (The Toronto Star, 2011). The Indian National Congress decided to support both production and consumption of 
"Khadi" (home-based cotton apparel, spun and made at home). Since then, Khadi has been used as a political sign of the Indian National Congress.

Even though Khadi played a very important and symbolic role during the Independence period, the core nature of production of Khadi did not change from 1947 to the late 1970s. First, a focus on home-based apparel manufacturing did not fuel technological advancement within the industry. Therefore, apparel manufacturing still remained at home with few opportunities to grow. Second, the government also kept Khadi manufacturing at individuals' home, particularly in the rural areas, by calling it one of the village industries - " any industry located in a rural area which produces any goods or renders any service with or without the use of power and in which the fixed capital investment per head of an artisan or a worker does not exceed one lakh rupees or such other sum as may, by notification in the Official Gazette, be specified from time to time by the Central Government" (The Khadi and Village Industries Commission Act [KVIC Act], 1956). Therefore, under this law, the Indian apparel manufacturing firms have been categorized as rural small- and medium-sized handcraft enterprises (SMEs) as they were mostly located in the rural areas and had a capital investment of less than Indian National Rupee (INR, the national currency of India) one lakh (approximately U.S. \$ 2, 000 at the exchange rate of 2011) since 1956. In addition, the government viewed the handcraft industries as an important way to increase employment and incomes in rural areas, preventing villagers from moving to cities for jobs (Khaire, 2011). This resulted in keeping apparel manufacturing as a small-scale industry and Khadi as handmade products. 


\section{Current Indian Apparel Export industry}

Since 1970s, the Indian apparel industry has become a significant contributor to the Indian economy. Today, the apparel industry contributes approximately $14 \%$ to Indian industrial production, $4 \%$ to the Gross Domestic Products (GDP), and $17 \%$ to the country's export earnings (Ministry of Textiles, 2012). The Indian apparel industry is the second largest employment provider in the country (Apparel Export Promotion Council, 2012). India is the fifth largest exporter of apparel in the world exporting over US \$ 14.5 billion worth of apparel. (World Trade Organization, 2012).

Presently the Indian apparel sector is clustered in various regions across India. Das and Ha Brookshire (in review) found that the Indian apparel export industry is clustered in four regions. These regions are categorized as North, South, East and West. In the northern region, Delhi, Faridabad, Ludhiana, Jaipur, and Amritsar were found as the major apparel clusters. In the southern region, Bangalore, Tirupur, Chennai, and Coimbatore were found as the major apparel export bases. In the western region Mumbai and Ahmedabad were found to be the main apparel export hubs and in the eastern region, Kolkata was found to be main region with apparel export industries. .

\section{Figure 1: Map of India with Major Apparel Clusters}




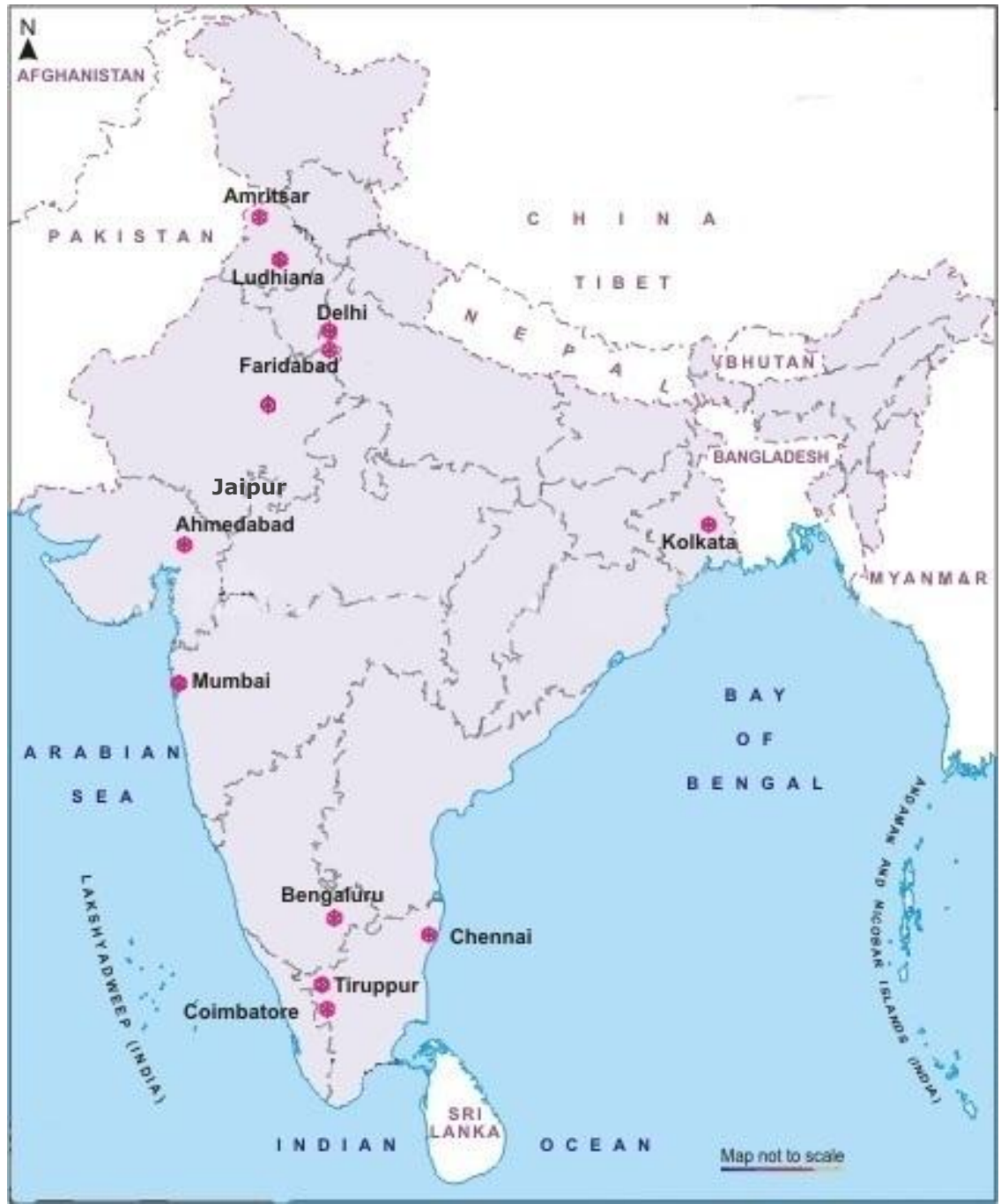

Adopted from Ministry of Textiles, India (2012)

The study found that the concentration of the Indian apparel export firms to be in the southern region of the country, with Tirupur (31.2\% of the study sample) being the most occurring place for the study sample, followed by Delhi $(21.2 \%$ of the study sample) and Bangalore (19.2\% of the study sample). The study also found 22 key resources claimed by the Indian apparel export firms. Content analysis of Web-based communication data revealed five firm resource categories that the Indian apparel exporters: (a) organizational knowledge and learning resources, (b) general 
organizational resources, (c) physical resources, (d) human resources, and (e) financial resources.

The firm resources were quality, experience in exporting, land or building infrastructure, location, equipment, size, good relationship with buyers, skillful workforce, quick or timely delivery, management, product breadth, affordable or competitive price, customer satisfaction, domestic operations, reputation or recognition, design, certificate, skillful designer, financial resources, domestic manufacturing or brands, Fashion trend knowledge, and awards. Particularly, organizational knowledge and learning resources, such as quality, timely delivery, competitive price, physical resources such as location, infrastructure, and equipment, and general organizational resources such as experience in exporting were most frequently mentioned key resources by the Indian apparel export firms.

Although these are important findings, the key resources found by Das and HaBrookshire (in review) are not the actual resources possessed by the Indian apparel export firms. Rather, they are the key resources claimed by the businesses. They might be true key resources or something that they want to achieve. Given, key resources as one of the most important factors described by Porter's (1998) diamond model, it is extremely important to understand what are the key firm resources that Indian apparel exporters have to compete. Consequently, due to the possible gaps between the actual resources and the resources claimed by the Indian apparel export firms, this study proposes:

Research question 1: What are the key resources that the Indian apparel exporters actually have for their competitive advantages as described by the company's leaders? 


\section{ANALYSIS OF THE INDIAN APPAREL EXPORT INDUSTRY THROUGH PORTER's DiAMOND MODEL}

\section{Firm strategy and structure}

Among many different firm strategies and structures that may affect firms as proposed by Porter (1988), in this study, firm ownership type is being considered as the focus. Firm ownership has been regarded as a specific factor in developing and maintaining key firm resources (Chang \& Ha-Brookshire, 2011). The examples of different firms that may have different ownership types in this study are firms owned by domestic people or firms (hereafter, domestic ownership), firms owned by foreign people of firms (hereafter, foreign ownership), and firms owned jointly between domestic and foreign partners (hereafter, joint venture).

A study by Akuratiyagamage (2005) on the Sri Lankan apparel export industry found that joint venture companies provided a more supportive environment for learning to create an effective organizational environment and development of firm resources. The study also found significant differences between joint venture companies and domestic companies in managing, developing, and maintaining organizational resources. The study by Chang \& Ha-Brookshire (2011) found that firms with domestic ownership place more emphasis on physical, financial and general organizational resources compared to firms with non-domestic ownership.

Analysis using firm ownership type is important because the Indian apparel export industry has unique history regarding firm ownership. The Indian Government did 
not allow foreign direct investment in its apparel sector till the early 1990s. This means, that Indian apparel firms with more than 20 years of experience are domestically owned. While newly established firms have more influences from foreign investors and are mostly joint venture organizations. The Indian Government has been relaxing its FDI policies since 1991, and the revision of trade policies in 2006 has allowed foreign investors to enter the apparel sector in the form of franchising, and joint ventures (Textile Intelligence, 2007). A recent study by Apparel Export Promotion Council (2011) found that there is a distinctive mix of organized and unorganized apparel manufacturing and export firms in India. The difference in ownership types can be said to be one of the reasons. To further understand why there is a distinctive mix of organized and unorganized apparel manufacturing and export firms in India, this study proposes:

Research Question 2: How ownership types (domestic and non-domestic) shape and influence the development and maintenance of Indian apparel exporters' key resources?

\section{Demand conditions}

Demand conditions as described by Porter (1998) explain how domestic demand constantly pushes companies to innovate and upgrade. While sophisticated home demand forces firms towards better products and services, varying levels of sophistication in consumer demands lead to market segmentation. However, in this study, we are looking into international demands and how international demands help develop firm resources. That is because exporters' customers are foreign buyers and consumers, and therefore, condition of foreign demands is an important factor for exporters' competitive 
advantages. Therefore, in this study, the characteristics of foreign demands from Indian apparel exporting firms are of a focus.

EU was the biggest destination for apparel exports, with over US\$ 5.3 billion worth of exports for the year 2011-2012. US was the second biggest destination for apparel exports, with exports of US\$2.85 billion for the same period (Ministry of Textiles, 2012). Similarly, Das and Ha-Brookshire (in review), found that $45 \%$ of the study samples were exporting apparel to European Union, while only $25 \%$ of the study sample was exporting apparel to United States.

Given that the demand conditions of EU and the US consumers are distinctly different, we can expect that the key firm resources would also be different between Indian apparel exporters who supply their products to the European market and Indian apparel exporters who supply to the United States. Consequently, the study proposes:

Research Question 3: How do Indian apparel exporters' key firm resources differ for different buyers with different market conditions?

\section{Related and supporting Industry}

The textile industry is the most closely related to the apparel export industry, and its competitive position in the global market provides a great benefit to apparel export. Therefore, for an apparel industry to be successful, it is critical for the textile industry to be supportive, according to Porter (1998). The textile industry is one of the most important sectors in the Indian economy and is the largest organized industry in the country in terms of employment (nearly 14 million workers) and number of units (Ministry of Textiles, 2012). 
India ranks seventh in the world production and trade of textiles and is the world's largest producer of jute and the second largest producer of cotton, silk and cellulosic fiber. It ranks sixth in terms of clean wool production, and fifth in man-made fibers production (Ministry of Textiles, 2012). The Indian textile industry has been the most supported industry by the Indian government and experienced steady growth in the past few decades. Howeverdue to an increase in cotton prices in 2010, there had been some disruptions in the textile outputs.

The textile dying industry is also currently going through a lot of change. The Madras High Court ordered the dyeing unit owners situated near Tirupur to remain closed as it failed to conform to zero discharge of effluents and releasing toxic effluents into the Noyyal river (TOI, 2011). The use of Technology Upgradation Funds (TUF) for implementing the technology of zero discharge of toxic waste into the environment has not been effective (CNBC, 2011). Though the dyeing industry has resumed operation, the number of dyeing industries has declined dramatically and is affecting the garment sector in Tirupur (The Hindu, 2011).

Given there have been major changes and disruptions in textile and dying industry the apparel industry could be affected. In addition, the agriculture industry, and chemical industry could have also affected the Indian apparel exporters' strategies. However, as we do not know how these changes in the supporting industries influence the apparel export firm's resources, the study proposes,

Research Question 4: How do the supporting industries shape and influence Indian apparel exporters' key resources? 


\section{Government Export promotion policies/strategies}

Porter (1990) describes how governments affect the above four determinants by playing the roles of consumer, policymaker, and commerce regulator. The government acts as "a catalyst or challenger" when it encourages or pushes companies to increase their performance in order to gain competitive advantage. Indian government has historically protected its textile and apparel industry from foreign competition through high tariffs and quantitative restrictions. Recently, however, Indian government has been relaxing trade policies. To promote export, foreign direct investment and generate revenue, Indian government has taken various steps and we are going to discuss few of them.

\section{Technology Upgradation Fund (TUF)}

The Government of India (GOI) introduced the Technology Upgradation Fund (TUF) scheme in 1999 to overcome technological obsolescence in the textile and apparel industry by infusing capital for modernization of the infrastructure and machinery, which in turn enhances the Indian apparel export sector. (Ministry of Textiles, 2012).

The $\$ 6$ billion fund, which was made available for a 5-year period beginning on April 1, 1999, is expected to address the industry's technology needs, especially in the weaving, processing, and apparel sectors, and enhance its global competitiveness. Under the TUF scheme, textile and apparel units may be eligible to receive medium- and longterm loans from the Industrial Development Bank of India (IDBI), the Small Industries Development Bank of India (SIDBI), and the Industrial Finance Corporation of India at interest rates that are 5 percentage points lower than the normal lending rates of these institutions. (Ministry of Textiles, 2012). 


\section{Infrastructure development schemes and Apparel Exports parks}

The poorly developed infrastructure of India is one of the biggest hurdles for foreign buyers and FDI. In response, the government has been improving the situation by collaborating with private companies to build new highways, metro, and airports (Halepete \& Iyer, 2008). Especially, the Indian Government has taken an initiative to set up infrastructure for the textile and apparel industry. Localized manufacturing parks are being created to facilitate small to mid-sized industries to compete with the global markets (Ministry of Textiles, 2012). Government of India launched the "Apparel Park for Exports" scheme in 2002, for imparting focused thrust for setting up of apparel manufacturing units of international standards at potential growth centers (AEPC, 2002).

Despite all of these government's policies and encouragements, the Indian apparel export sector has not enjoyed steady growth as analysts expected. Currently, there is no clear answer available. Therefore, to help answer this question, the study proposes:

Research question 5: How government policies and support shapes and influences Indian apparel exporters' key resource development and maintenance?

\section{Chances}

Events or occurrences that are outside of control of the firms, industries or even governments are called chance (Porter, 1988). Disasters, wars, economic sanctions, oil shocks, economic or political crises, and great technological innovations are examples of chance. Indeed, there might be pure chances for success for Indian apparel exporters. Economic recession is one of the critical changes for most businesses. However, we have little knowledge on the type of chances that Indian apparel exporters are currently facing. 
Furthermore, how much chances affect Indian apparel exporters' key resource development is unknown, so the study proposes:

Research question 6: How "chances" shape and influence Indian apparel exporters' key resource development and maintenance?

\section{Summary of research gaps and questions}

Although the RBT, Porter's diamond model, and subsequent research on firm resources have helped improve our understanding of the general and export firms maintenance, and sustaining their competitive advantages, we still have little knowledge on the key resources that would help Indian apparel export firms' competitive advantages, as well as the factors shaping and influencing these firms' key resource management. To help fill this gap, the study was designed to gain a deeper understanding on 'what Indian apparel export firms have to achieve and maintain competitive advantages in the global marketplace' and 'what influences such firms' key resource development and maintenance', in order to guide current and future Indian apparel export performance and to offer a better picture of the effectiveness of the Indian government's strategies in the global marketplace.

More specifically, the objectives of the study are to gain an in-depth knowledge of the unique firm resources actually possessed by the Indian apparel export industry and to understand the various factors such as ownership, government support, business environment and trade agreements affecting the development of resources for sustained competitive advantage. 
Although these are important findings, these are not the actual resources possessed by the Indian apparel export firms but are found to be the resources claimed by them. Because of the gap between the actual resources and the resources claimed by the Indian apparel export firms, this study proposed:

Research Question 1: What are the key resources that the Indian apparel export firm's actually have for their competitive advantages as described by the company's leaders?

Research Question 2: How do ownership types (domestic and non-domestic) shape and influence the development and maintenance of companies' key resources?

Research Question 3: How do Indian apparel exporters' key firm resources differ for different buyers with different market conditions?

Research Question 4: How do supporting industries shape and influence Indian apparel exporters' key resources?

Research question 5: How do government policies and supports shape and influence Indian apparel exporters' key resource development and maintenance?

Research question 6: How do "chances" shape and influence Indian apparel exporters' key resource development and maintenance? 
Figure 2: The Study Framework as it pertain to Indian Apparel Export Firms

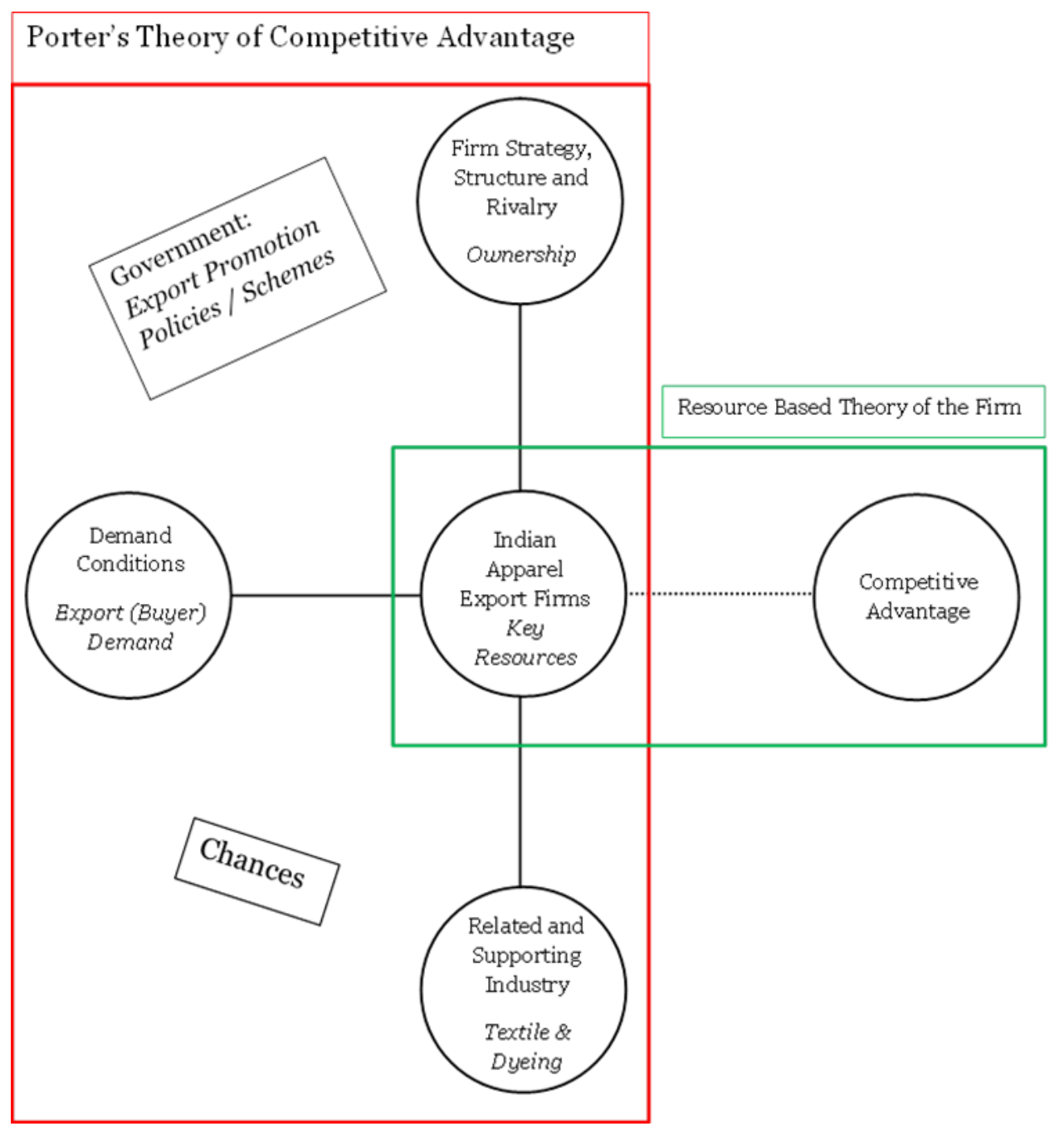

Figure 2 illustrates the study framework. The framework uses Porter's

Competitive Advantage of Nation's model to understand how the individual conditions affect, shape and help in development of firm's resources. The Indian apparel export firm's resources are analyzed by studying how export / buyer demand, ownership types, textile and dyeing industry, government's export promotion policies, and chances influence, shape firm's resources and in turn provides competitive advantage to the Indian apparel export firms. 


\section{ChAPTER III: MeThOdology}

Chapter III contains the following sections (a) qualitative interview, (b) sample (c) data collection, (d) validation strategies, and (e) data analysis.

\section{Qualitative Interview}

The aim of the study was to gain an in-depth knowledge of the unique firm resources actually possessed by the Indian apparel export industry and to understand the various factors such as ownership, government support, business environment and trade agreements affecting the development of resources for sustained competitive advantage. To achieve this objective, a semi structured qualitative interview approach was used in order to explore the actual resources that Indian apparel firms have. Because no study currently exists that examines the actual resources possessed by Indian apparel firms, a qualitative approach to data collection and interpretation formed the methodological basis of this study. Qualitative research is used to study research problems in which little are known about the problem (Creswell, 2005).

Because of the exploratory nature of the study, semi structured interviews were used as an appropriate research design. The reason why a semi structured interview was chosen in this study over either a structured or non-structured interview is because structured interviews may take some opportunities away from some interviewees to offer real and meaningful information, whereas non-structured interviews may make the comparison of information more difficult because each interview might cover different questions (Gillian \& Cassell, 1998). Core questions deemed central to the objectives of 
this study was asked to all respondents. Interviews were conducted until the research questions were answered and no new themes emerged.

\section{Sample}

To find a group of interviewees representing India's apparel manufacturing and export sector, a list was developed in the following three ways: (a) through a business directory, (b) through personal contacts, and (c) through firsthand information of several major apparel companies. The study by Das and Ha-Brookshire (in review) found that the majority of the apparel manufacturing and export firms are located in southern region of India and were recruited.

Once the sample framework was established, the study samples were selected through purposive sampling technique. This method of purposive sampling is used when the aim is to select people who possess specific characteristics in order to illuminate the phenomenon being studied, rather than to select a representative sample drawn from a population (McCracken G. , 1988).

The sample of participants were chosen based on the different ownership types and on the different foreign buyers to provide sufficiently different perspectives throughout the Porters' Diamond Model..

After the approval of the university's Institutional Review Board, a total of eighteen participants were recruited. All the participants were interviewed at their offices in Tirupur and Bangalore. All the participants represented the top management of their companies. Among the participants, four each were managing directors and chief executive officers, three each were factory managers and directors, two each were general managers and company owners. Seven of the participants had less than ten years of 
association with the current companies, while remaining eleven of the participants were working in the same companies for more than ten years. Table 1 presents the participant description.

Table 1: Demographic Characteristics of Participants

\begin{tabular}{|c|c|c|c|c|c|c|}
\hline $\begin{array}{l}\text { Sl. } \\
\text { No. }\end{array}$ & Participant* & $\begin{array}{c}\text { Title } \\
\text { Company* }\end{array}$ & $\begin{array}{l}\text { Associated } \\
\text { with the } \\
\text { Company }\end{array}$ & Location & Ownership & $\begin{array}{l}\text { Major } \\
\text { Buyer }\end{array}$ \\
\hline 1 & Ajay & $\begin{array}{l}\text { Chief Executive Officer } \\
\text { ABC International }\end{array}$ & 12 & Tirupur & Domestic & Europe \\
\hline 2 & Karthik & $\begin{array}{c}\text { Managing Director } \\
\text { BCD Apparel Ltd }\end{array}$ & 7 & Tirupur & Domestic & Europe \\
\hline 3 & Amit & $\begin{array}{l}\text { General Manager } \\
\text { CDE Garments }\end{array}$ & 18 & Tirupur & Domestic & $\begin{array}{l}\text { Europe } \\
\text { \& USA }\end{array}$ \\
\hline 4 & Sayan & $\begin{array}{c}\text { Factory Manager } \\
\text { DEF Knitss Pvt Ltd }\end{array}$ & 11 & Tirupur & Domestic & Europe \\
\hline 5 & Bikas & $\begin{array}{l}\text { Managing Director } \\
\text { EFG Textiles Ltd }\end{array}$ & 5 & Tirupur & Domestic & $\begin{array}{l}\text { Europe } \\
\& \text { USA }\end{array}$ \\
\hline 6 & Neel & $\begin{array}{l}\text { Chief Executive Officer } \\
\text { FGH Apparel exports }\end{array}$ & 6 & Tirupur & Domestic & $\begin{array}{l}\text { Europe } \\
\& \text { USA }\end{array}$ \\
\hline 7 & Suman & $\begin{array}{l}\text { Managing Director } \\
\text { GHI Garments }\end{array}$ & 4 & Tirupur & Domestic & $\begin{array}{l}\text { Europe } \\
\& \text { USA }\end{array}$ \\
\hline 8 & Raj & $\begin{array}{l}\text { Owner (Proprietor) } \\
\text { HIJ International }\end{array}$ & 8 & Tirupur & Domestic & Europe \\
\hline 9 & Rahul & $\begin{array}{l}\text { Director (Operations) } \\
\text { IJK Apparels }\end{array}$ & 10 & Tirupur & Domestic & $\begin{array}{l}\text { Europe } \\
\text { \& USA }\end{array}$ \\
\hline 10 & Sanjay & $\begin{array}{l}\text { General Manager } \\
\text { JKL Knitting Ltd }\end{array}$ & 12 & Tirupur & Domestic & Europe \\
\hline 11 & Ashok & $\begin{array}{l}\text { Director (Marketing) } \\
\text { KLM Apparel Ltd }\end{array}$ & 15 & Tirupur & Domestic & Europe \\
\hline 12 & Sachin & $\begin{array}{c}\text { Chief Executive Officer } \\
\text { LMN Clothing Company } \\
\text { Ltd. }\end{array}$ & 14 & Tirupur & Domestic & $\begin{array}{l}\text { Europe } \\
\& \text { USA }\end{array}$ \\
\hline 13 & Sagar & $\begin{array}{l}\text { Factory Manager } \\
\text { MNO Knitss Pvt Ltd }\end{array}$ & 8 & Tirupur & Domestic & Europe \\
\hline 14 & Rajiv & $\begin{array}{l}\text { Director (Sourcing) } \\
\text { NOP Fashions }\end{array}$ & 5 & Tirupur & Domestic & $\begin{array}{l}\text { Europe } \\
\& \text { USA }\end{array}$ \\
\hline
\end{tabular}




\begin{tabular}{ccccccc}
15 & Akash & $\begin{array}{c}\text { Owner (Proprietor) } \\
\text { OPQ Clothing Ltd }\end{array}$ & 16 & Bangalore & Domestic & $\begin{array}{c}\text { Europe } \\
\text { \& USA }\end{array}$ \\
16 & Sid & $\begin{array}{c}\text { Chief Executive Officer } \\
\text { PQR Apparels Pvt Ltd }\end{array}$ & 10 & Tirupur & Jt. Venture & $\begin{array}{l}\text { Europe } \\
\text { \& USA }\end{array}$ \\
17 & Nikhil & $\begin{array}{c}\text { Factory Manager } \\
\text { QRS Garments Pvt Ltd }\end{array}$ & 6 & Bangalore & Jt. Venture & Europe \\
18 & Samir & $\begin{array}{c}\text { Managing Director } \\
\text { RST Fashions Pvt Ltd }\end{array}$ & 8 & Bangalore & Jt. Venture & $\begin{array}{l}\text { Europe } \\
\& \text { USA }\end{array}$ \\
\hline
\end{tabular}

Note. * All participant's names and company names are pseudo names.

Participants' company characteristics are as follows. Eight of the export firms exported exclusively to Europe, while the remaining ten export firms did business with both United States and Europe. Three companies were non domestic in nature, while the remaining fifteen companies were domestically owned. Fifteen of the companies were located in Tirupur while the remainder three were located in Bangalore. Among the companies studied, ten of the firms were in operation for more than twenty years, while six of them were in operation for more than ten years but less than twenty years and two of the firms had less than ten years of operational experience.

All of the companies were involved in producing knitwear, however among them two companies were also involved in woven wears. Twelve of the companies were producing women wear, eight of them were producing kids wear, four of the companies were exporting all product categories, while one each of the export firms were manufacturing and exporting menswear and intimate wear. Seven of the companies had export sales of less than one billion US dollars. Five of the companies had export sales of more than one billion US dollars but less than five billion US dollars, while remaining five companies had export sales over five billion US dollars. Four of the companies employed less than 500 workers, eight of the companies had more than 500 employees 
and less than 1000 employees, while remaining six companies had more than 1000 employees. Table 2 presents company descriptions.

Table 2: Demographic Characteristics of Indian Apparel Export Firms

\begin{tabular}{|c|c|c|c|c|c|}
\hline $\begin{array}{l}\text { Sl. } \\
\text { No. }\end{array}$ & Company* & $\begin{array}{l}\text { Years in } \\
\text { Operation } \\
\text { (Years) }\end{array}$ & Product Category & Export Sales & $\begin{array}{l}\text { No. of } \\
\text { Employees }\end{array}$ \\
\hline 1 & ABC International & 21 & Knit (Kids wear) & US \$ 650 million & 430 \\
\hline 2 & BCD Apparel Ltd & 15 & Knit (Intimate wear) & US\$ 720 million & 600 \\
\hline 3 & CDE Garments & 28 & Knit (All product types) & US $\$ 1.2$ billion & 520 \\
\hline 4 & DEF Knitss Pvt Ltd & 22 & Knit (All product types) & US\$ 850 million & 670 \\
\hline 5 & EFG Textiles Ltd & 12 & $\begin{array}{l}\text { Knit (ladies and kids } \\
\text { wear) }\end{array}$ & US\$ 540 million & 400 \\
\hline 6 & $\begin{array}{l}\text { FGH Apparel } \\
\text { Exports }\end{array}$ & 16 & $\begin{array}{l}\text { Knit (ladies and kids } \\
\text { wear) }\end{array}$ & US $\$ 1.5$ billion & 850 \\
\hline 7 & GHI Garments & 15 & $\begin{array}{l}\text { Knit (Ladies and Kids } \\
\text { wear) }\end{array}$ & US\$ 6 billion & 1200 \\
\hline 8 & HIJ International & 6 & Knit (Ladies wear) & US\$ 350 million & 190 \\
\hline 9 & IJK Apparels & 12 & Knit (All product types) & US $\$ 3.5$ billion & 850 \\
\hline 10 & JKL Knitting Ltd & 21 & Knit (Ladies tops) & US $\$ 8.5$ billion & 1500 \\
\hline 11 & KLM Apparel Ltd & 15 & Knit (All product types) & US $\$ 12$ billion & 1200 \\
\hline 12 & $\begin{array}{l}\text { LMN Clothing } \\
\text { Company Ltd. }\end{array}$ & 28 & $\begin{array}{l}\text { Knit (kids and ladies } \\
\text { wear) }\end{array}$ & US\$ 15 billion & 1600 \\
\hline 13 & MNO Knitss Pvt Ltd & 22 & $\begin{array}{l}\text { Knit and woven (kids \& } \\
\text { ladies wear) }\end{array}$ & US\$ 400 million & 270 \\
\hline 14 & NOP Fashions & 12 & $\begin{array}{l}\text { Knit (High Fashion } \\
\text { Ladies wear) }\end{array}$ & US\$ 920 million & 600 \\
\hline 15 & OPQ Clothing Ltd & 16 & $\begin{array}{l}\text { Knit (kids \& women } \\
\text { wear) }\end{array}$ & US $\$ 3.5$ billion & 720 \\
\hline 16 & $\begin{array}{l}\text { PQR Apparels Pvt } \\
\text { Ltd }\end{array}$ & 15 & Knit (ladies wear) & US $\$ 8$ billion & 1100 \\
\hline 17 & $\begin{array}{l}\text { QRS Garments Pvt } \\
\text { Ltd }\end{array}$ & 9 & $\begin{array}{l}\text { Knit \& Woven (kids \& } \\
\text { women wear) }\end{array}$ & US $\$ 1.8$ billion & 550 \\
\hline 18 & $\begin{array}{l}\text { RST Fashions Pvt } \\
\text { Ltd }\end{array}$ & 12 & $\begin{array}{l}\text { Woven (women \& } \\
\text { menswear) }\end{array}$ & US\$ 57 billion & 34000 \\
\hline
\end{tabular}


Note. * All company names are pseudo names

\section{Data Collection}

The study used in depth semi structured interviews as a data collection method. Because of the sensitivity of identity informed consent forms were created, to suffice the university's IRB review. The word usage of these consent forms were in common English, in Hindi, in Tamil, and in Kannada so as to be understood by anyone.

In depth semi structured interviews were utilized to allow the participants to describe and define the key resources. After an explanation of the study and assurance about confidentiality, all participants were asked to give their consent, and whether their interview accounts may be recorded. In addition, the participants were briefed on the methodology and purpose of the study. The interviews took place in a location of participant's choice and lasted approximately one hour to ninety minutes. If the qualified person does not speak English or Hindi (the main researcher is a native Hindi speaker), then a suitable person with the knowledge of English and Tamil or Kannada was to be found within the same company to do the translation. However all the participants were comfortable in interacting in English and hence all the interviews were conducted in English.

In following the interview process, general questions regarding participants' background and experience in the apparel industry initiated the interview. Subsequently, questions led into defining the resources possessed by the firm. Then investigating how the participant describes the areas of ownership, business environment, and government support. The interview concluded with reflective questions on how the participant's perceptions on the future of the Indian apparel industry. 
Pilot run: The initial interview for the pilot data collection was conducted on Tuesday, October 31, 2012. The pilot run's initial interview took place in the participant's residence in Columbia, Missouri. The participant is a graduate student and has three years of experience of working in an export house as merchandiser. IRB approval for the pilot run was deemed not necessary.

The interview started out with the basic company information regarding the companies export turnover, years of operation, main product category and number of employees and moved to the basic demographic information regarding the participants work history and current status and position in the company. The remainder of the interview was divided into six categories, which are illustrated in the interview section, as firm resources, ownership types, demand conditions, supporting industries, government policies, and chances.

Following the structure of the interview schedule, the next category prompted the participant to describe the firm resources of her company. This is achieved by asking questions about the unique strengths, weakness about her company. Also, information regarding the ownership types was collected by asking about the history of the company and by asking to describe the growth path of the company. However the responses to ownership type interview questions were found to be centered on the organizational structure and did not provide a clear picture on ownership of the firms' influence on shaping and developing of firm. The participant responded to the ownership interview question as

“........our top most buyer, a German based leather retailer, has been doing business with us for the past 10 years and now they want to have more control in 
production and quality; so they invested in our organization. They wanted to have a factory under their total control so that their product lines were only manufactured there and they had a greater control on quality".

The participant did not provide any information how this joint venture helped the export firm in developing and shaping the firm resources. Next the participant was asked about her reflections on the buyer demand conditions and how it affected her firm resources. The participant provided descriptions about the buyer and what are their specifications and requirements but did not provide any clear information about the buyer's involvement in shaping their firm resources. The participant was more interested in describing the buyer and the buyer's importance to the export house than describing the firm resource development due to buyer's requirements.

"How do your foreign buyers help your organization in developing certain skill set or knowledge? They give a broader outlook, because we learn a lot about their working culture, their demands, their perfectionist nature, no compromising mentality, and these helped us in improving our employee skills. They motivate you to venture, try out new styles, new color sets and is always so competitive. These demands really helped in improving my management skills".

The participant was next asked to describe the supporting and related industries that affected her company. The participant was asked to describe about the government policies that helped her company in export and about any "chance" that may affect her firm. The participant could not provide any insight into the government policies influencing and shaping the firm resources. She pointed out that she being a merchandiser, she was more involved with maintaining a good consumer (buyer) 
relationship and so does not have a good idea of the government policies that are affecting the development of the firms' resources. The participant pointed out recession as a "chance" condition which helped her firm in better managing financial resources and also helped in developing physical infrastructure for small product orders.

From the pilot run, additional interview questions in understanding the firms' ownership types, buyer demand conditions, and chances deemed necessary in answering the study's research questions. Thus, the present interview questions on ownership types were refined and changed to include the understanding of the effect on firm resources due to ownership types. Therefore, an additional interview question was added to include. Also more interview questions centered on buyer demand conditions were constructed.

All other interview questions deemed appropriate for the purpose of the study.

\section{Validation Strategies}

The validation strategies utilized to ensure validity in this study were (a) researcher's reflexivity, and (b) participant's feedback

Reflexivity was a continuous strategy throughout the duration of the research and analysis as "the researcher is an active participant in qualitative researcher" (Anderson \& Jack, 1991). The researcher's past experiences, bias, and involvement was addressed, to help the reader understand how these factors could have affected the collection and interpretation of the data.

Participant feedback would have helped the researcher do an external check of the validity of the data and the interpretations concluded with the participant's involvement. The researcher sent via email, the theme interpretations, along with the summary of the findings to five participants asking for their reactions and feedback. Because of the busy 
schedules of these participants', none of the participants' reviewed or replied. The member check would have helped to strengthen the validity of the study's theme interpretations and overall study framework. As the emails were sent to five participants on April $22^{\text {nd }}, 2013$, the researcher is still expecting to get the participant's feedback within the next few days.

\section{Data Analysis}

The interview transcripts were transcribed into Microsoft Word documents. After the transcribing was completed, the data were coded and interpreted by emerging themes with the aim to uncover the actual resources possessed by the Indian apparel firms. Also adherence to the university's IRB board, all subjects and materials were coded. All names were changed to pseudo names. Following McCracken (1988), the analysis moved from the particular (a detailed analysis of language in each transcript) to the general ( a comparison of patterns and themes across all the transcripts). A cyclic process of breaking the data up and arranging the data together into themes eventually helped in establishing patterns and corresponding categories. 


\section{CHAPTER IV: RESULTS}

Chapter 4 contains (a) theme interpretation and (b) researcher's reflection.

\section{Theme Interpretation}

Interpretation of the study data was divided into the key competitive advantages, the unique key resources, ownership types shaping key resources, unique resources for demand conditions, supporting industries shaping key resources, government policies and supports and chances shaping the key resources, following the Porter's diamond model.

The first section, key competitive advantages, discovered the competitive advantages that the top management of the Indian apparel export firms described. The second section, the unique key resources was explored through the research question one. The third section, ownership types shaping key resources of the Indian apparel export firms was explored through research question two. The demand conditions, the different key firm resources for different buyers with different market conditions, explored research question three. Supporting industries and government policies shaping the key resources formed the fifth and the sixth section and explored research question fourth and research question fifth respectively. The seventh section, chances affecting the unique resources, explored research question sixth.

\section{Key Competitive Advantages}

First, unique key resources were identified that provided competitive advantage to the Indian apparel export firms. These unique firm resources helped to understand and 
identify the different factors that influenced and shaped the Indian apparel export firm's competitive advantage. In exploring the key resources of the Indian apparel export firms, the results of data analysis revealed four distinct competitive advantages. These competitive advantages were (a) product advantages that the Indian firms gained through high quality, (b) price advantage gained through competitive product pricing, (c) on time delivery advantage through infrastructure, and (d) service advantage through customer satisfaction and good supplier relationship.

\section{Product advantage}

In exploring the unique key resources of the Indian apparel export firms, product advantage emerged as a prominent theme category. Sixteen participants described ability to maintain and provide quality product as a key competitive advantage. This competitive advantage was found to be consistent with the Chinese textile and apparel industry (Chang \& Ha-Brookshire, 2011). High quality was found to be an important key resource in the Chinese textile and apparel industry. While Chinese companies seemed to be focusing on the best quality in the world by expressing "high quality" ; approximately 12 of the study participants seemed to mean the quality by level that would satisfy their buyers so that they do not have to repeat the production. Ajay puts quality to be the "right quality" and for him, the quality checking system at the forefront of the production system makes this possible:

Ajay: We have a very rigid quality checking system in our factories. We always try to manufacture the right quality product at the very first time, and we have been quite successful in that. 


\section{Price Advantage}

Price advantage emerged as another important theme category. Fourteen participants described ability to provide products at a competitive price as a competitive advantage. Interestingly, however, price never came up as a key competitive advantage for the Chinese textile and apparel manufacturers. Das \& Ha-Brookshire (in review) found competitive pricing as a key competitive advantage for the Indian apparel exporting firms. Price advantage did not necessary mean lowest price. Out of the 14 participants, 10 stressed the importance on the ability to maintain a "competitive price" so that they can sustain their business. Karthik, [a Managing Director of an apparel export firm], stated that he was able to run his business that is narrowly focused, because of his firm's competitive pricing strategies. For him, these competitive prices played "a major role" in getting orders, in return, profits.

Karthik: We make products at a very competitive price. As we are exporting only undergarments, price plays a major role. So we always try to book orders at a very competitive price so that we can maintain our business.

Nikhil, a young factory manager working at a non-domestic owned export house, described Indian apparel business to be controlled by "affordable" product price. He felt that if the "affordable price" could not be met then running business will become more difficult. He felt that the price cushion that the manufacturers and exporter's used to enjoy is long gone and the Industry is facing a very stiff competition from both domestic export firms and also from apparel manufacturing and export firms in Bangladesh and China. 
Nikhil: Now we don't even have the cushion of making any production delays. The lead times [the total time period from order receiving to order dispatching] have shortened and the margins have reduced. We have to provide goods at a very affordable price or else we lose business to Bangladesh and China.

\section{Delivery Advantage}

Ability to deliver products on a timely manner emerged as the third important recurring theme. Installing state-of-the-art machinery and developing the infrastructure seemed to be an important resource for the Indian apparel firms, 11 participants stated infrastructure as a key firm resource. Interestingly, some of the previous research showed Indian apparel firms did not have proper infrastructure for global competition (Lu \& Karpova, 2011). However, in this study, participants emphasized the quality of infrastructure, consistent with Chinese textile and apparel firms (Chang \& HaBrooskhire, 2011).

Developing and implementing production systems to increase productivity and to ensure on time delivery was found to be an important key firm resource. The point to note here is that the investment of Indian apparel firms' in infrastructure and increasing productivity is a fairly new phenomenon as 7 out of 11 mentioned that they have just started implementing these efforts. Four participants described "lean systems" and two participants described "production management software" as their infrastructural development activities. Amit, a general manager of a domestic owned apparel export firm, stated "lean systems" and "order tracking software" as key resources to maintain and sustain on-time delivery for his firms:

Amit: We have started implementing lean systems in our factories. We are installing a software called "Connect World" [pseudo name] which is primarily for planning and management software. It will help in tracking orders and remove 
bottlenecks from the system. We are sending 5 to 6 percent of our orders by air, and I believe that by implementing this PMS software [Connect World] I will be able to reduce this air shipment to 0 to 1 percent.

\section{Service Advantage}

Ability to provide customer satisfaction and maintaining good buyer relationships was found to be another important key resource to maintain service advantage. Nine out of eighteen participants described customer satisfaction as a key resource and seven participants out of them also stressed the importance of maintaining a good relationship with the buyer as key resources for their firms to attain competitive advantage. This resource seemed consistent with the Chinese apparel and textile industries. Chang and Ha-Brookshire (2011) found customer satisfaction as a key resource among the Chinese apparel and textile industries to attain competitive advantage.

"To satisfy buyers" was found to be an important trend among the participants, as Sayan described. Sayan, a factory manager with an apparel export firm, stated that they try to satisfy the buyer by fulfilling all their needs. It seemed that he is even "ready to walk an extra mile, whenever they are asked" to satisfy the buyers by providing them with new product samples.

Sayan: Our main goal is to satisfy our buyers. We are always trying to fulfill the needs of our buyers by providing them with new product samples whenever they ask for.

Samir, a Managing Director of a non-domestic apparel export firm, described "buyer and supplier relationship" as a very important firm resource. According to him 
"networking" in today's economy is the biggest competitive advantage. It not only helps in securing future orders but also helps in sourcing raw materials at a cheaper price.

Samir: For us, being able to develop a good relationship with the buyer is of utmost important. We cannot lose buyers in today's economy. We are trying to improve and strengthen our networking so that we can ensure future orders from the same buyer. Also maintaining a good supplier relationship over the years has led to the development of a reliable partner and it has helped us in sourcing raw materials at a competitive price.

\section{Key Resources of the Indian Apparel Export Firms}

The unique key resources of the Indian apparel export firms as described by the managers were categorized into (i) human resource, (ii) quality standards, (iii) physical infrastructure, and (iv) product development and design. Each of these key resources revealed different themes. The themes under human resources were (a) training, (b) employee welfare, (c) quality talent hiring. Under quality standards, the themes that were identified were (a) independent quality standards and (b) specific system for specific buyer. Physical infrastructure resources gave rise to different themes. They were (a) infrastructure for on time delivery, (b) infrastructure to reduce poor quality, and (c) infrastructure to increase productivity.

\section{Human Resources}

The most important key firm resources described by the managers were found to be human resources. Fifteen participants described employees, workers, operators and human resource management as the most important key resource of their organization. It was also interesting to find that the participants not only stressed on the importance on 
providing training to the employees but also actively invested on employee welfare schemes. This key resource was found to be consistent with the previous study on the Indian apparel and textile industry. Lu \& Karpova (2011) found abundant skilled workers and labors as an important key resource for the growth of India's apparel and textile industry. However, Lu and Karpova (2011) never found that training and employee welfare is an important resource in India's apparel and textile industry, while Chang and Ha-Brookshire (2011) found training as a important human resource in Chinese textile and apparel industry.

Training for "ensuring uniform quality": Eight participants stated "training" as an important key resource development process. Training seemed to be a method used by the Indian apparel export firms to maintain a uniform quality across its production lines. Particularly, Amit [General Manager of an export firm] puts training is an "essential tool" to achieve different quality standards for different buyers:

\begin{abstract}
Amit: Training is mandatory for every employee. However, we do provide special training to our checking [quality assurance] section. The training of our checking staff takes place according to the requirements of our [each of our four] buyers' quality levels.
\end{abstract}

Five participants stated training as a process for employee retention and gaining the loyalty of the employees. Bikas [Managing Director of a domestic owned export firm] states that when employers pay for the employees' training, the employees take the training more seriously and highly motivated to learn new skills, for example paid internships or paid operator training. According to him, this resulted in the internal growth of the employees as well as the success of the organization. As the employees 
became more satisfied with their jobs and performed well, they were less likely to leave the company and search for other jobs.

Bikas: Every new employee is provided with a paid-four-week training. The new employees learn about our organization from the training program. This training helps us in retaining employees and it has also reduced the labor turnovers.

Three participants stated training as a "recruiting" tool. High School students were provided with part time trainings. The companies hired a government training agency to provide free training to these students at their schools. Ashok [Director of sourcing of an apparel manufacturing and exporting firm] puts training as a method to "develop future employees" so that they can easily hire skilled labors.

Ashok: We recruit students from villages to take part in our training programs. We provide them [students above the age of 16] with part time training and also help them in their education. This helps us [the companies] in not only in developing a pool of future employees but also these young employees are found to be loyal and hardworking.

\section{Employee welfare programs as a "loyalty creating process": Seven participants}

described employee welfare as a key resource for human resource management. It was interesting to see that the participants were very actively describing their employee welfare programs. Establishing childcare centers, providing them with health care benefits, providing pension benefits were found to be few of the employee welfare programs that the participants practiced for employee welfare programs. Surprisingly, all these welfare programs come under the basic necessity that a factory has to provide to the employees under various Indian labor protection laws and acts. For example, the 
Employee State Insurance act (1948) states that employers are liable to provide health insurance facilities to employees, the Employees' Provident Fund act (1952) states that the employers will provide provident fund and pension facilities to employees who have worked for the organization for a period of 15 years, the Bonus act (1962) states that employees are entitled to bonus and increments (Ministry of Labor and Employment India, 1948) Employee welfare programs were not described in the earlier literature. It may be because, these welfare programs constitute the basic employee amenities and are already being provided in other sectors of the industry. Neel, the chief executive officer of an export firm, described employee welfare programs as a "loyalty creation process" among the employees. He stressed on "free education, free food" provided to the children's of the employees. It seemed that the free services motivated the employees in sending their children's to these welfare programs. Neel also stated that the children's being in a child care facility relieved the employee tensions and they were more productive in their jobs.

Neel: Loyalty of our workers. We take care of the needs of our workers. We have our own school where the children's get free education. We also provide free food for the children studying in our school. Also we provide after school care for the children if the workers have to work overtime.

Though creating loyalty seemed to be main reason behind starting the welfare programs, few (three) of the participants described these welfare programs as a method of giving back to the society. Quarterly health screening of the employees was found to be a common method practices by these companies. Suman [Managing Director of an apparel export firm] described these health screening processes as a method of "ensuring health 
standards" among his employees. The apparel industry being a labor extensive industry, Suman felt that these health screenings plays a vital role in identifying any health risks among his employees. Also, this welfare programs seem to reduce the absenteeism rate in his factories.

Suman: We provide quarterly health screening facilities to all of our employees. This ensures the health standards of our employees. We also provide them with free basic medicine. This has reduced labor absenteeism dramatically. I feel proud to be associated with such a program where I can give back something to the society.

Quality hiring for "hiring the best": Hiring of quality talent was found to be another important human resource development tool. Four participants described "hiring the best" as a key resource for their success. "Knowledge of the industry and experience in handling orders" were found to be key criteria behind hiring new employees. It was, however, interesting to see that "training" was seen as a burden by these companies. As Raj [owner of a apparel manufacturing and exporting firm] puts "hire people with good knowledge" as a tool to compensate the lack of loyal employees and thus reducing the burden of training them.

Raj: Nowadays, you cannot expect everybody to be loyal to us. So, we always try to hire people who has a good knowledge and experience so that we don't have to train them [i.e. hiring the best]

Also, it seemed that these participants achieved an increase in productivity and quality by "hiring the best". Rahul, a factory manager, described his supervisors as one of the best in 
the industry. It seemed that he has a huge confidence on these "production managers from Srilanka, fabric supervisors with post graduate degrees".

Rahul: We have very qualified human resources. We hire the best to do the job. We hired production managers from Srilanka, fabric supervisors with post graduate degrees. This has not only increased our productivity but also has improved our factory quality.

\section{Quality Standards}

The next most important firm resources were found to be quality standards. Eleven participants described product quality, quality systems and quality levels as an important key resource of their organization. It was interesting to find that the participants put a lot of emphasis on the quality of their products. It seemed that quality as one of the reasons for the export firms to get regular orders from the same buyers. Das \& Ha-Brookshire (in review) also found quality as an important firm resource for the Indian apparel export firms.

"No need to search for orders" because of universal quality standards: To be self-independent in terms quality seemed to be common theme among the Indian apparel export firms. Eight participants described "a uniform quality standard throughout the factory" as a key tool in maintaining product quality. "Own quality standards" practiced by the Indian apparel export firms seemed to generate "good name" for the Indian firms. It also seemed that the Indian apparel firms are getting ready to manufacture for the domestic Indian market. Samir, a managing director of an Indian apparel export firm, stated "I have my own quality standards. We are thinking of launching our own domestic 
brand in the future". Sanjay [a general manager of an apparel export firm] was proud to announce that he has a "1.5 AQL [Acceptable Quality Level] though out his factory irrespective of his buyers". It seemed he has become more confident in producing high quality products by practicing a rigid uniform quality system. It also seemed as if he was happy at being able to avoid the confusions of different buyer's product quality that he had to maintain in the past.

Sanjay: We try to maintain a product quality of 1.5 AQL [Acceptable Quality level] throughout our factory irrespective of buyers' quality standards. By improving and maintaining our own quality standards we have earned a good name for ourselves [independent quality standards].

Getting continuous orders seemed to be connected with product quality. However it was interesting to see that the managers were thinking of long term benefits and not compromising quality for short term profits. "Maintaining a good quality" seemed to be an attractive firm quality for foreign buyers. The exporters seemed confident with the flow of orders that they were able to achieve due to their ability to maintain a good quality over a period of time. As Ashok [Director of Marketing of an apparel export firm] puts it, it seemed he was very confident of "sufficient orders" and that he does not have to "search" for orders. Particularly, Ashok, associates low price with poor quality .It seemed that he was trying to differentiate their quality from cheap price goods from China.

Ashok: We don't want to compromise our quality based on the price. We have maintained a good quality over a long period of time [reputation building among foreign buyers due to stable quality standards]. Today we have sufficient orders and we don't have to search for orders. 


\title{
"Factory within a factory system" by specific quality system for specific buyer:
}

It was interesting to find that managers described specific quality systems for specific buyers as a tool to maintain quality standards. Four participants described "specific quality systems for specific buyers" as a method to produce buyer specific quality products. "Different product lines" and "different teams" for different buyers seemed to be a solution to produce different styles from different buyers under one factory. As Ajay [chief executive officer of an apparel export firm] puts "a factory within a factory system" seemed to be a tool to maintain buyer specific quality.

\begin{abstract}
Ajay: To increase productivity and to deliver different quality standards for different buyers we have separated the production lines. From procuring raw materials to shipping we have separate production and merchandising teams for each buyer. We have a factory within a factory system.
\end{abstract}

A rigid quality system for specific high end buyers was another method used by the firms to maintain quality standards. It seemed that "providing continuous quality products" served as a way to obtain customer satisfaction. The exporters measured the "strength" of buyer exporter relationship by gaining continuous orders from them. It was interesting to find exporters working with only one buyer so that he can provide the right quality and satisfaction to the buyer. As Rajiv [ Director of an apparel export firm] puts it "we work with only one buyer so that we can maintain their quality standards and good relationship with the buyer". It seemed that maintaining a "good relationship" with the buyer was very important for the exporters. "Recession" and "less orders" may be one of the reasons behind the extra care taken by the Indian apparel exporters to maintain a good 
relationship with the buyers to attain continuous orders. As Suman [managing director of a apparel export firm] states the buyers' "total faith" in his company was the most important resource for his company to survive through recession and even more successful today.

Suman: We have developed a rigorous quality system which allows us to work with high-end buyers. Because of our reputation of providing good quality commitments we are able to work to our full strength even in the recession period. Buyers have total faith in us. And this has been achieved by providing continuous quality products over the period of time.

\section{Productive physical infrastructure resources}

The next most important firm resources were found to be physical resources. Development of infrastructure, implementing lean systems and overhead hanger systems were found to be important tools to develop the physical resources. Fourteen participants described physical resources as an important key firm resource. The participants put a lot of emphasis on developing the physical infrastructure to have a productive system. It was interesting to see that the managers described their physical infrastructures for improving the productivity of their factories than developing the infrastructure for large orders. Das \& Ha-Brookshire (in review) similarly found physical resource as a unique key firm resource of the Indian apparel export firms. However, in the Chinese textile and apparel Industry (Chang \& Ha-Brookshire, 2011) physical resources were found to be an important firm resource. 
"Reducing travel time" by reducing poor quality: Having a total vertically integrated facility was often described as a method to reduce poor quality. The managers described a vertically integrated facility as having all the facilities except spinning for apparel production and export. "Reducing travel time" and "all facilities under one premise" was found to be a way to reduce poor quality as it eliminated bundle mix-ups and confusions created through fragmented [all facilities scattered at different places] production systems. Raj states that having a vertically integrated facility "under one premise" helped him in "managing his product better".

Raj: Having everything under one premise helps us in keeping track and maintain good quality. It also reduces the travel time and in return helps in managing our products better.

Installing new state-of-the-art machinery seemed to be another way of reducing poor quality. Upgrading the machinery and installing automatic systems seemed to be an effective way to reduce quality issues. The managers also stressed not only upgrading and installing new production equipment but also trying to upgrade all the machineries all throughout the factory. As Neel [chief executive officer of an apparel export firm] states a "new printing system" was installed, not only to reduce fabric waste but also to improve the overall product quality.

Neel: We installed a new screen printing system in our factory so that we can reduce the fabric wastage [by reducing fabric wastage, the company is able to reduce product price]. It has also helped us in improving the quality of our products. 
“Eliminate wastes' by on time Delivery: Developing the physical resource to eliminate manual movement of bundles, streamlining productions and increasing productivity were found to be the tools used by the managers to ship goods on time. Installing automatic hangars on modular production systems, for automatic transportation of garment bundles from one operation point to another, was also found to be a method used by the managers to increase productivity and reduce overall costs. Improving the "facilities" in the factory seemed to be important. As Rahul [Director of an apparel export firm] puts we "introduced lean production systems" to increase productivity, "reduce quality issues", and "eliminate wastes".

Rahul: We are always trying to reduce and maintain our overhead costs and to do so we have improved the facilities of our factory so that we can eliminate wastes. We have introduced lean production system to increase our productivity and also provided on line checking system to reduce quality issues.

Using modular systems to reduce production time and using "garment hangar system" to improve productivity, seemed to be a tool being used by the Indian apparel export firms to deliver their products on time. These tools seemed to be providing a breathing time to the apparel export firms and this extra time helped them in balancing their shortfalls and still maintain their delivery schedules. As Bikas states "the cushioning time" helps his factory to adjust other production factors and it helps them in to deliver products on time.

Bikas: Our factory has an automatic hangar system. After installing this system we have reduced our sewing time by $15 \%$ and this has helped in creating a 
cushion. The cushion helps us to adjust lead times and we are able to deliver most of our goods on time.

Increase in Productivity through "shared responsibility": It was interesting to see that the Indian apparel export firms are working so hard in improving the productivity of their factories. Lu and Karpova (2011) found Indian apparel and textile firms to be the least productive units compared to China and Bangladesh. Improving the productivity of the factories through infrastructure and human resources seemed to be the tools used by the managers. Improving the productivity of the work force through "shared responsibility" was described by Amit [general manager of an apparel export firm] as a method of improving labor productivity.

Amit: In our organization, every individual is the owner of their responsibility. The responsibility is shared. Our competition is with ourselves. We try to better our own statistics. And because of these we have a very efficient production system with state of the art technologies which help us in detecting any bottlenecks real-time.

Modern computing systems, tracking devices, automatic hangar systems were found to be the tools used by the managers to improve the infrastructure and this improved productivity. "Lean system" was found to be a popular system among the managers trying to improve the productivity. As Sachin [chief executive officer of an apparel export firm] states "very first company to implement lean system", emphasizing the importance of the lean system to improve his factory's productivity. 
Sachin: We have a system that monitors and tracks orders on a real-time basis. We were also among the very first companies in Tirupur to implement Lean systems in our factory to improve our productivity.

\section{Product Development \& Design}

The next most important firm resources were found to be product development and design. Hiring designers, buying computer related design software, developing product development teams were found to be the methods of developing the design and product development knowledge. Four participants described design and product development as an important key firm resource. The participants put a lot of emphasis on developing the own design samples for foreign buyers as a method of gaining future orders. It was interesting to see that the managers described their design and product development knowledge as a method of insuring future orders. Das \& Ha-Brookshire (in review) found similar resource as a unique key firm resource of the Indian apparel export firms.

Three participants stated "design and product development knowledge" as an important firm resources. Two participants described "design software" and "skilled designers" as a key firm resource. Particularly Nikhil [Factory Manager of an apparel export firm] puts design as an essential tool to achieve extended customer satisfaction.

Nikhil: Design and product development knowledge are very essential resources for today's market. It helps us in providing buyers design samples and thus provides them an additional option to look for. 


\section{Ownership}

The unique key resources of the Indian apparel export firms that were influenced and developed by the company's ownership were (a) human resource, (2) quality standards, (3) infrastructure, (4) product development and design, and (v) on time delivery. Majority of the participants (15 out of 18) interviewed were found to be of domestic ownership type. The key resources that were found to be influenced by this ownership type were (i) on time delivery, (ii) quality, and (iii) customer satisfaction. However the non-domestic owned organizations (3 out of 18) influenced (i) human resources, (ii) quality standards, and (iii) product development and design.

Chang \& Ha-Brookshire (2011) found that, in the case of China, firms with domestic ownership placed more emphasis on physical, financial and general organizational resources compared to firms with non-domestic ownership. Though it may not be appropriate to compare the differences between the resources developed due to ownership type, it was interesting to see that Indian firms with domestic ownership developed physical, and general organizational resources and firms with non-domestic ownership developed human and organizational knowledge and learning resources.

Resources Gained through Domestic Ownership: General organizational resources such as good relationship was found to be an important key resource among the domestically owned companies. Nine out of the fifteen companies stressed maintaining a good and friendly relationship with both the buyer and supplier as an important resource for their success. Maintaining a good relationship with the buyer was found to be an important key resource in the Chinese textile and apparel industry (Chang \& HaBrookshire, 2011), however good relationship with suppliers was never found to be an 
important key resource. As Raj states "suppliers play a vital role in manufacturing goods at a competitive price" emphasizing the importance the suppliers play in their business decision making.

Raj: We [with domestic ownership] have always maintained a very good relationship with our suppliers. In todays' economy, they play a vital role in manufacturing goods in a competitive price. They can make or break a company, considering today's rising cotton prices.

Physical resources such as infrastructure development seemed to be a major resource to be associated with domestic owned companies. Seven out of the fifteen participants stressed on the importance of developing "the infrastructure to attain competitive advantage". Tewari (2005) found physical resources such as infrastructure as an important resource of Indian textile and apparel industry.

It was also interesting to find that many (6 out of 15) of the participants believed that having a domestically owned organization is helping them in making quick, important decisions. Raj [Owner of an apparel export firm] describes this quick decision making freedom in a domestically owned organization as a "money saving" criteria. He stated that "time is money" and being the head of the firm and not having to answer to anyone for his decisions, he is able to take effective, quick and immediate decisions which in the long distance saves money. Though it may seem to be true in this case, most of the firms which have a corporate structure will not have a single person for decision making. 
Raj: I take my own decisions. Being independent actually helps me in working faster. I don't have to rely on anyone for taking a decision. And so it helps in the long run in saving money.

\section{Resources Gained through Non-Domestic Ownership: Human resources and}

organizational knowledge and learning resources such as product development and design were found to be important resources among the non-domestic owned companies. Human resources such as employee training and employee welfare were found to be an important criteria for the non-domestic owned companies. Also developing own designs and product development was found to be a vital resource for these non-domestic owned companies to attain competitive advantage. As Nikhil [factory manager of an apparel export firm] states "providing design solutions to [foreign] buyers" helps the companies in many ways. Sid [chief executive officer of an apparel export firm] describes these advantages in a four stages. First, the buyers would have more "design choices" [as the exporters are also developing designs for the buyers] to choose from. Second, once their design is selected they can directly start production as sampling is already done in the design development process which "reduces the lead time' [has intricate knowledge about the garment and so can foresee the difficult operations]. Third, in production they already know the processes and their quality of production is much better with fewer "production wastes". Fourth, the buyer becomes "dependent' on the export firm as it provides an extra value added service [by providing design and product development services]. Therefore, for firms with foreign ownership it seems to provide unique value added services in design to foreign buyers. Lu \& Karpova (2011) and Tewari (2006) stated that Indian apparel and textile industry specializes in orders with high design 
details. Developing own designs can be seen as a next step by Indian apparel export firms.

Sid: By having our own designers and product development teams we are able to provide design samples to our buyers. This has helped us in growing bigger. Now, we have buyers who want us to design for them.

\section{Demand Conditions}

Quality, infrastructure, good relationship and human resources were found to be the key resources influenced by the demand conditions. Out of the 18 firms analyzed, 7 firms exclusively exported to the European Union (EU), three firms exclusively exported to the United States (US) and eight firms exported to both the United States and EU. Das and Ha-Brookshire (in review) found the Indian apparel export industry to be more inclined towards the EU compared to US in doing business. The key resources found to be influenced by EU's demand conditions were (i) quality and (ii) good relationship; and by US' demand conditions were (i) infrastructure and (ii) human resources.

It was found that export firms working with EU buyers seem to develop a more stringent quality system not only in production but also in fabric dyeing and printing processes. Also, the orders from EU buyers are generally small in quantity with intricate design details. It was also found that 7 of 18 export firms in this study favored working with EU buyers as they were more comfortable in communicating with the buyers and also the EU orders had a higher margin. As Rahul [Director of an apparel exporting firm] put it, "we are more comfortable working with European orders" emphasizing that not only does he have a good relationship with the European buyers but also the profit margin is higher. Though quality is a stringent criterion for European buyers, it seemed 
that the Indian apparel export firms were comfortable with the EU quality standards. Sagar [factory manager of an apparel export firm working with only European buyers] describes working with European buyers as a total improvement of their quality standards from fabrication to packing.

Sagar: One of the strongpoints that we have is quality. We have met the quality requirements of our buyers not only in garment production but also in fabrication, dyeing and printing. This is a main reason why we are still doing business with the same buyers for the past 7 years.

Export firms working with US buyers seem to have developed a huge infrastructure and are capable of manufacturing large quantity orders. The export firms working with US buyers seemed to be more concerned about increasing their productivity, in turn, low cost. It was also found that the firms usually did simple basic design orders for the US buyers. It was interesting to see that the US buyers were more concerned with labor welfare and human resources. The export firms working with US companies emphasized being a "child labor free" organizations with "ISO 9001 certifications". As Raj states "working with US buyers is tricky" emphasizing that relationship building is not a key factor when working with US companies, but productivity, on time delivery and proper human welfare systems are. Samir [managing director of an apparel export firm] describes US orders as a bulk production and thus employs a large number of workers.

Samir: We employ 34,000 workers, we have 25,000 machines and we produce 10,000 garments daily. Our vertically integrated system allows us to work at a very competitive price [for U.S. buyers]. 


\section{Supporting Industries}

Spinning Industry was found to be the main supporting industry of the Indian apparel export firms. Twelve out of the eighteen participants stated spinning industry as the main supporting industry. Competitive price and good supplier relationships were found to be the key competitive resources gained through the supporting industry. The Indian textile industry is one of the major industries where India enjoys a competitive advantage. India is also the second largest producer of cotton in the world (Ministry of Textile India, 2012). Tewari (2005) stated the textile industry as a key resource of the Indian apparel export firms as it provides availability of cheap raw materials. As Akash [owner of a apparel export firm] states that the spinning industry is the main supporting industry as it controls the quotation prices and can "make or break" an order emphasizing the importance of the spinning industry in being able to produce garments at a competitive price. Rahul [director of an apparel export firm] describes the supporting industry as a "family".

Rahul: Over the years I have been able to maintain competitive prices due to the suppliers. I can always rely on them. They have become a part of my family.

The dyeing industry was found to be another important supporting industry. Four participants described the dyeing industry as a very important part of the supply chain. It may be due to the recent dyeing crisis that the participants are considering the dyeing industry as an important supporting industry. Sayan [factory manager of an apparel export firm] stated all the process as important supporting industries. It seemed that he 
was evaluating each of the processes of the supply chain to measure which one is the most important supporting industry.

Sayan: Dyeing industry is definitely an important supporting industry. Actually all the different processes such as spinning, weaving, knitting, manufacturing, finishing, logistics are all important. If any of one of these processes is shut down we will not be able to export garments.

\section{Government Policies}

The main government policies that were found to influence the key resources of the Indian apparel export firms were the export subsidy, apparel parks and the technology up-gradation funds. It was interesting to see that all the 18 participants stated the government's export promotion schemes and policies as a failure. Sixteen of the participants stated these government policies as lacking long term goals and objectives, resulting in negative impact on these firms' competitive advantages rather than improving them. Three major themes emerged: (a) export subsidy, (b) apparel parks, and (c) technology up-gradation funds.

Export Subsidy: The Indian government provides an export subsidy to the Indian textile and the apparel industries. Fifteen participants described this export subsidy to be negatively affecting their firms. This subsidy lowers the market price of the textile products below the domestic market price in the foreign market and thus helps the competitors of the Indian apparel export firms in sourcing raw materials at a cheaper rate than Indian apparel export firms. Akash [owner of an apparel export firm] describes export subsidy as "double edged knife". He states that though it may seem to benefit the 
Indian apparel export firms, but it is actually hampering their business. Neel [chief executive officer of an apparel export firm] states that if the "advantage" and "disadvantage" of the export subsidy was calculated, then it would have been stopped a long time ago.

\begin{abstract}
Akash: Our competitors, like Bangladesh is sourcing raw materials from Indian textile companies at a cheaper price due to the export subsidy. This is affecting our product prices and we are losing orders.
\end{abstract}

Also the export subsidy is in violation with the WTO, and thus is affecting many of India's free trade agreements. Indian government is in talks with EU to develop a FTA (Free Trade Agreement) in apparel exports. However due to the violation, this process has slowed. On the contrary Bangladesh enjoys a FTA with EU and also with India in the apparel export sector. This has affected the Indian apparel export firms. Seven participants stated that the delay in the FTA has led to losing business to Bangladesh apparel export firms.

Raj: Originally our prices are cheaper compared to Bangladesh. However due to the lack of FTA, we are losing orders which we should get.

Also four of the participants felt that due to the FTA between India and Bangladesh, the domestic Indian apparel market is also getting affected. Companies who produce for both export and domestic sector are facing the same competitor. Amit [General Manager of an apparel manufacturing firm] while describing the FTA stated that the "Indian government's insensitivity" towards the apparel manufacturing sector will harm the Indian economy in the long run. Karthik [Managing Director of an apparel 
export firm] wanted the domestic apparel sector to be "protected" so that at least domestic manufacturers can survive.

Apparel Parks: The apparel parks set up for promoting investors to develop apparel export firms seem to have backfired. Eleven participants stated that lack of planning in setting up of apparel parks has led to failure of the scheme. Sanjay [General Manager of an apparel export firm] stated that the apparel parks are set up without providing the necessary infrastructure of proper transportation and electricity. Sagar [Factory manager of an apparel export firm] stated unavailability of abundant and skilled labors as another factor in the failure of the apparel parks.

Raj: The apparel parks have not helped us in anyway. Though it was set up at a Special economic zone (SEZ), the unavailability of labor and lack of essential infrastructure has negatively affected the scheme. $75 \%$ of the Netaji Apparel Park, today is still empty.

Setting up of apparel parks near existing apparel export hubs has not helped the Apparel park promotion scheme. Sid [Chief Executive Officer of an apparel export firm] stated that the "human resources" and other physical resources such as "constant supply of electricity" have been compromised due to setting up of an apparel park near an existing apparel export hub.

Sid: The government policies are many times impractical. How can two apparel export hubs, each having at least 500 medium and large export houses, at a distance of $20 \mathrm{~km}$ apart, survive? 
Technology Up-gradation funds: These funds were allocated by the Indian government to encourage the Indian apparel export firms to upgrade their machinery. However, due to the inefficient and clumsy bureaucratic system, this has also seemed to have failed. The reimbursement process for the funds is so complex that 7 out of 18 participants stated that they do not want to apply for the technology up-gradation funds. The participants described their experience as very frustrating and tiring. Rajiv [Director of an apparel export firm] describes the technology up-gradation funds as a "trap" and stated that "taking bank loans" is much better option than applying for technology upgradation funds. Rahul [Director of an apparel export firm] shared that he had to "cancel" order and had to bear losses due to TUFS.

Rahul: We applied for the TUFS funds for a special machine for a particular order, but there was so much delay in getting the funds that we had to cancel the order.

\section{Chances}

Recession was found to be the main chance factor affecting the key resource of the Indian apparel export firms. Sixteen participants said that recession as a "chance" that had affected them and has influenced in developing and restructuring their key resources. Although two participants shared the strict regulations on the dyeing industry, the majority of them share an economic recession being the biggest chance that affected their way of businesses. It was interesting to see that recession positively affected the Indian apparel export firms. It helped in reducing the wastes prevalent in the Indian apparel export industry. Due to recession most of the firms had to cut down their overhead costs 
which prompted the firms to improve their labor productivity by installing new production systems. That is, the economic recession in fact helped these firms be more productive in a positive way. It was also due to recession that Indian apparel export firms started investing in developing designs and product development. Quality improvements and developing infrastructure for on time delivery was developed to reduce overhead costs and wastes. It can be said that though recession slowed down the business, it brought out the inefficiencies of the Indian apparel export industry into the open.

Sid: Before I was never concerned about my labor efficiencies. Now I have hired an Industrial engineer to improve my productivity. I am also planning to implement six sigma in my factory to reduce wastes.

\section{Summary of Results}

The Indian apparel export firms' competitive advantages were found to be product, price, delivery and service advantage. Product advantage was achieved through sustained quality standard practices. Price advantage was achieved through reducing wastes and improving productivity. Delivery advantage was achieved through development of infrastructure, and Service advantage was achieved by maintaining a good buyer and supplier relationship and customer satisfaction. The key main resources of the Indian apparel export firms that were found in this study were of human, physical, quality and product development and design of the Indian apparel export firm. Ownership type, demand conditions, supporting industries, government policies and chances do 
effect and influence these key resources of the Indian apparel export firms. A pictorial representation of the major theme categories and themes emerged are shown in figure 3.

\section{Figure 3: Summary of the Results as it pertains to Indian Apparel Export Firms}

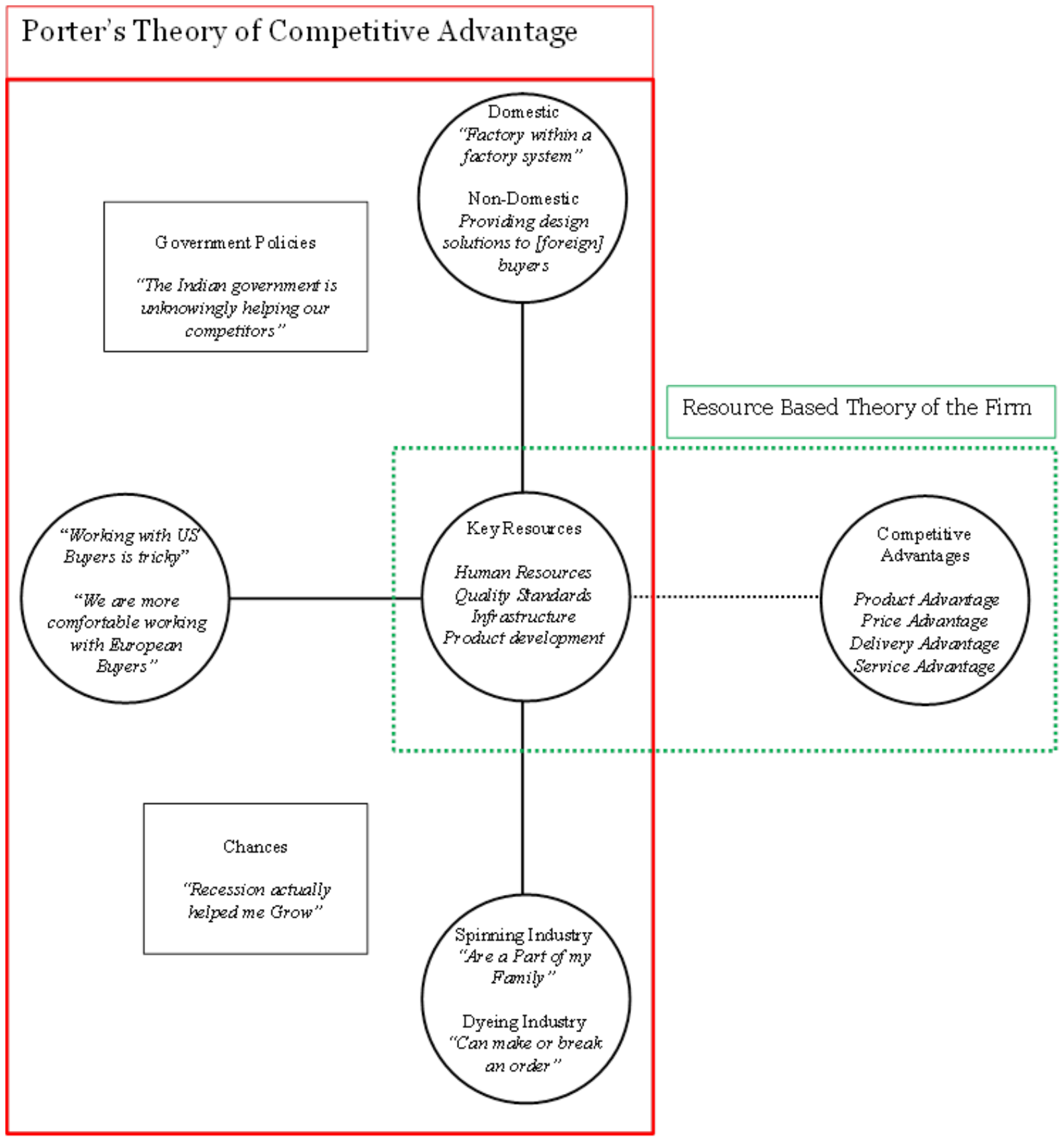




\section{Researcher's Reflection}

Throughout the process of this research, this reflective section was the most overwhelming to write, perhaps because I was finally forced to insert myself into the study and this filled me with fear and anxiety. When I was working in the apparel industry in Tirupur, India, I always felt that Indian apparel export sector will improve and will be an important part of Indian economy. Also I always felt that a country with more than one billion population and clothing being a basic necessity of the people, the textile and apparel sector will be one of the most important sectors for the Indian Government. However, now with the findings from this study, I feel more disturbed and in fear in answering whether the Indian apparel sector will flourish in the coming years or it is a dying industry.

The time I spent with my participants, during data collection, was memorable and exciting. I was amazed at seeing the openness and excitement of the top managers, executives and company owners on speaking about their firm's competitive resources. They allowed me to ask questions freely and shared their personal feelings and experiences while answering questions pertaining to government's role, recession, buyers and supplier relationships. However, when talking about their competitive advantages, I felt that the participants were more political in answering the questions. I was shocked to see how the data collection affected and shaped my previous perceived notions about the Indian apparel industry. Two weeks I was in Tirupur and Bangalore were both physically and emotionally draining for me. After conducting the interviews, I was overwhelmed at times from observing and hearing the struggles, obstacles and sacrifices the participants faced due to working in the apparel export sector. Though at the beginning of the study I 
believed that the Government's support and export promotion policies are helping the Indian apparel sector, however after conducting the interviews I was asking myself "Was this how I felt, when I was in the industry?"

I tried to keep an objective perspective during data analysis and after stepping back from the interpretations, I was surprised to see how Porter's model fit into this study. In the beginning I considered analyzing only demand, firm structure and strategy, and supporting industries for understanding the key competitive advantages of the Indian apparel export firms and leave out Government and chances from the study. However after completing the study, I was glad that I included all the factors of the Porter's model as it provided a complete picture of the factors affecting and influencing the Indian apparel export firms.

At the onset, I expected that demand conditions, firm structure, related industries, and government to positively affect the Indian apparel export firm's resources. I also expected chances such as "recession" to negatively affect the firm resources. To my surprise, Government was found to negatively affect the Indian apparel firm's resources and chances was found to positively affect the Indian apparel export firms in developing their competitive resources.

This research has been a very personal experience and while interviewing the participants I felt the connection between them and me. The participants wanted to share their difficulties and it seemed that they were using this study as a mode of telling the world about themselves. I do find myself in dilemma, as I always wished that the Indian apparel and textile industry has a high growth rate, similar to the Chinese apparel \& textile industry but I found the exactly opposite result from the study. However due to 
this study, I find myself more connected with the industry. I feel happy for having taken a small step in understanding the problems of the Indian apparel export firms.

\section{Chapter V: Conclusions}

Chapter 5 contains the following sections (a) summary of the study, (b) contributions, (c) implications, and (d) limitations and future research.

\section{Summary of the study}

The aim of this study was to gain a deep understanding of the actual firm resources possessed by the Indian apparel export firms. The study data is viewed through Porter's (1990) theory of competitive advantage of nations and Barney's (1991) resource based theory. The different conditions, such as factor conditions, demand conditions, related and supporting industry, firm strategy, structure, government and chances were used to analyze the Indian apparel export firm' competitiveness.

In defining the factors influencing the resources of the Indian apparel export firms, data analysis revealed that ownership type influenced the physical and the organizational knowledge and learning resources positively. Domestic ownership types seemed to improve their physical resources such as infrastructure to build their production capacities. However, non-domestic owned companies were found to build their design and product development skills to improve their competitive advantage.

It was interesting to find that buyer type positively influenced the Indian apparel export firms' competitive resources. It was found that European buyers influenced the quality development of the export firms, while U.S. buyers influenced the productivity 
improvement of the apparel export firms. The spinning industry was found to be main supporting industry and good relationship with this supporting industry was found to influence the competitive price of the manufactured products of the apparel export firms.

Government policies were found to negatively affect the competitive resources of the Indian apparel export firms. Short term planning of the policies was found to be the main drawback of these government policies. The participants described the apparel export sector as a neglected sector from government's support. They felt that the rise of the information technology and software industry in India has replaced them. The participants felt that the "IT \& Software industry" is enjoying the "government support" that they used to enjoy a decade earlier.

It was also interesting to find that chances have positively affected the Indian apparel export firms' resources. The Indian apparel export industry known for its low productivity and efficiency has been trying to improve its productivity so as to be competitive. Cost cutting measures has led to improvement of the factory facilities and installation of various productivity improvement infrastructures.

\section{Contributions}

This study has several contributions to the literature. First, the study's finding support and expand Porter's (1990) theory. The study was also found to support the Barney's (1991) resource based theory. The different conditions mentioned in Porter's model helps in understanding the relative competitive advantages of a nation's specific industry. In this study we used the model to understand the Indian apparel export firm's competitive advantages. Also it helped in understanding the different factors influencing 
the Indian apparel export firm's key resources. The resource based theory of the firm defines competitive advantage as a "value creating strategy" being implemented by a firm while other potential competitors do not or cannot and in this study we see competitive price and design and product development as a value creating strategy by the Indian apparel export firms. Competitive price and design and product development knowledge were found to be important factors influencing the competitive advantage of India's apparel export sector which was not found before and thus adds to the literature.

Second, the findings provide an understanding of the important key firm resources unique to Indian apparel export firms and will provide insights into the different factors influencing the development and maintenance of these unique key firm resources. Competitive pricing, product development and design, and human welfare programs were found to be important key firm resources claimed by Indian apparel export firms. These insights provide a comparative picture of the Indian apparel export firms.

Third, by exploring the key firm resources of the Indian apparel export firms, the study findings may help firms who are interested in investing in the apparel export sector in India to prepare themselves with these key unique resources they must develop, obtain, and improve when they invest or start a new business in India. For example, foreign investors might be more willing to invest in design and product development knowledge, while domestic investors may be more willing to invest in physical resources.

Fourth, this study contributes to the development of students in apparel academic units preparing for a future career in the apparel industry. Expected findings may help add to the existing curriculum to incorporate knowledge and skill sets to help the Indian apparel export industry achieve the unique key firm resources. This can assist in 
strengthening education for the future generation and assist them in selecting right job for them. Thus the study findings may be an important trend guide for educators and students in the apparel related programs in India to decide which skills and knowledge should be the program focus. For example, design curriculum, product development knowledge, human resource management skills may be included in the general curriculum to prepare the future entrepreneurs and prospective employees.

Finally, the study findings enrich and add depth to the firms' resources literature especially from the perspective of Indian exports in the apparel industry. The results may be useful for human resource departments in constructing and developing realistic job profiles. Additionally, businesses may be able to use the study's findings to help structure a stronger career development programs to ensure job satisfaction, which would help recruit and retain talented employees.

\section{Implications}

This study has implications for the industry, policy makers, and academia. First, this research offered opportunities for the participating firms to retrospect and evaluate their business strategies from different perspectives and helps them to understand what their unique key resources are. Throughout the data collection process, the participants were compelled to take an introspective look at their firm's competitive advantages.

Second, the study findings on the key unique resources of the Indian apparel export firms may help Indian firms in identifying their key resources and thus may help in improving them to attain competitive advantage. The Porter's model could help Indian 
firms in better evaluation of their key resources. Each factors of the Porter's model showed important influences on the participating firms' key resources.

Third, the apparel firms should consider working with one type of buyer, instead of trying to satisfy two different buyers. The Indian apparel export firms should concentrate on focusing on a set of resources which are best suited for a particular buyer. Indian apparel export firms may be able to maintain their competitive advantage by focusing on satisfying one type of buyer.

Fourth, policy makers may also discover the findings useful. The participants described the export promotion policies as "lacking long term goals" and found them to be negatively affecting their business. Also some of the participants described the government policies as "assisting" competitive countries firms. Policy makers may need to allow flexibility and continuous follow up on the policies implemented by the government. The participant found the bureaucratic delays as a discouraging factor in availing the government export promotion schemes. The policy makers may also need to fast track their technology up gradation funds allocation application and reimbursement policies to actually benefit the export firms.

Finally, the study's findings could greatly help academic departments in the apparel discipline. In preparing students for a future in the apparel industry, academic departments may find this study's findings useful for guidance and education purposes. Recent college graduates may enter the apparel industry unprepared for the industry's new key resources. The apparel discipline may incorporate the study's findings into coursework or career development programs to bring awareness to some of the unique value addition strategies being employed by the Indian apparel export firms. 


\section{Limitations and Future Research Opportunities}

As in other research, this study had certain limitations, and therefore future opportunities. First, this study purposively focused on the apparel export firms in Tirupur and Bangalore, India. Future research opportunities should look into other apparel export hubs. Future research should also try to compare the key resources among Indian apparel export firms situated in northern and southern region of India. The apparel export firms situated in northern region are close to the capital of the country and so may have a different response to government's export promotion policies. A national survey could be conducted to include a representative sample of firms exporting apparels.

Second, the study participants all belonged to the southern region of India. India, being a very diverse country in terms of culture, future research ideas could compare the northern and southern exporting firm's key resources. Also the southern firms being close to ports compared to northern firms, there may be new resources that could be learned from comparing the regions.

Third, the findings from this study are time, location and industry sensitive. Currently the Indian apparel industry is experiencing a slow growth due to the global economic downturn. This study comes after many Indian apparel firms' going bankrupt due to loss of orders. This affected each participant in some ways and could have influenced the findings. Therefore, future research should try to see how financial resources are influencing the Indian apparel export firms. 
Fourth, the study does not include global occurences such as the recent apparel accidents in Bangladesh as a Chance in the study. Future Study should investigate how does the Indian apparel export firms' resources are influences by these apparel accidents and how does the buyers response to these occurrences.

Finally, this approach being exploratory and qualitative in nature, generalizations of the results cannot be done. Large samples and quantitative studies should be undertaken to verify the actual key resources and competitive advantages of the Indian apparel export firms. 


\section{REFERENCES}

AEPC. (2002). Apparel Park for Exports. Retrieved October 24, 2012, from Apparel Export Promotion Council: http://www.aepcindia.com/market-Apparel-Park.asp

AEPC. (2012). About Apparel Export Promonotion. Retrieved August 25, 2012, from http://www.aepcindia.com/joinus.asp

Akuratiyagamage, V. M. (2005). Identification of management development needs: a comparison across companies of different ownership - foreign, joint venture and local in Sri Lanka. International Journal of Human Resource Management, 16(8), $1512-1528$.

Apparel Export Promotion Council. (2012). Apparel Export Promotion Council. Retrieved May 25, 2012, from http://www.aepcindia.com/joinus.asp

Barney, J. (1986). Organizational culture: Can it be a source of sustained competitive advantage? Academy of management review, 11, 656-665.

Barney, J. (1991). Firm resources and sustained competiive advantage. Journal of Management, 17(1), 99-121.

Bezić, H., Cerović, L., \& Galović, T. (2011). Changes in the competitive advantages of Croatia's Manufacturing Industry. Zb. rad. Ekon. fak. Rij, 29(2), 465-487.

Cavusgil, T., \& Zou, S. (1994). Marketing strategy-performance relationship: An investigation of the empirical link in export market ventures. Journal of Marketing, 58(1), 1-21. 
Chang, T.-T., \& Ha-Brookshire, J. (2011). Business activities, competitive resources and ownership types of Chinese textile and apparel manufacturing firms. International Journal of Fashion Design, Technology and Education, 4(2), 115-125.

CNBC. (2011, February 11). Money Control.com. Retrieved November 6, 2012, from CNBC TV18: http://www.moneycontrol.com/news/business/tirupur-spendingcroretech-to-revive-dyeing-industry_522353.html

Collins, C., \& Clark, K. (2003). Strategic Human Resource Practices, Top Management Team Social Networks, And Firm Performance: The Role of Human Resource Practices in Creating Organizational Competitive Advantage. Academy of Management, 46(6), 740-751.

Creswell, J. W. (2005). Educational research: Planning, conducting, and evaluating quantitative. Upper Saddle River, NJ: Pearson Prentice Hall.

Das, D., \& Ha-Brookshire, J. (in review). India, the Next China? Analysis of the Unique Firm Resources Claimed by Indian Apparel Export Firms. Journal of Fashion Marketing \& Merchandizing.

Dierickx, I., \& Cool, K. (1989). Asset stock accumulation and sustainability of competitive Advantage. Management Science, 35, 1504-1511.

Enz, C. (2008). Creating a competitive advantage by building resource capability: the case study of outback steakhouse Korea. Cornell Hospitality Quarterly, 49(1), 7378.

Gillian, S., \& Cassell, C. (1998). Qualitative methods and analysis in organizational research: A practical guide. London: Sage. 
Gonsalves, P. (2010). Clothing for Liberation: A Communication Analysis of Gandhi's Swadeshi Revolution. New Delhi: Sage Publications.

Grant, R. (1991). Porter's 'competitive advantage of nations': an assessment. Strategic Management Journal, 12(7), 535-48.

Jin, B., \& Moon, H.-C. (2006). The diamond approach to the competetiveness of Korea's apparel industry. Journal of Fashion Marketing \& Management, 10(2), 13612026.

Kathuria, L. M. (2008). An Analysis of Competitiveness of Indian Clothing Export Sector Using Porter's Model. The Icfai University Journal of International Business, 3(4), 39-46.

Lu, Y., \& Karpova, E. (2011). Comparative advantage of the Indian and Chinese apparel industries: an analysis of the global value chain. International journal of fashion design, technology and education, 4(3), 197-211.

McCann, J. (2011). China's Textile and Apparel Industry and the Global Market: Five Competitive Forces. S.A.M. Advanced Management Journal, 76(1), 33-54.

McCracken, G. (1988). The Long Interview. Newbury Park: Sage Publications. Ministry of Labor and Employment India. (1948) Laws related to Labor Welfare. Retrieved 6 3, 2013 from http://labour.nic.in/content/innerpage/labourwelfare.php

Ministry of Textiles India. (2012). Technology Upgradation Funds Scheme. Retrieved 6 20, 2012, from http://www.ministryoftextiles.gov.in/faq/faq_tuf.pdf Ministry of Textiles India. (2012). Annual Report. Retrieved 06 13, 2012, from http://www.texmin.nic.in/annualrep/ar_11_12_english.pdf 
Moon, H.-C., Rungman, A., \& Verbeke, A. (1998). A generalized double diamond approach to the international competitiveness of Korea and Singapore. International Business Review, 7(2), 135-150.

Penrose, E. (1959). The theory of the growth of the firm. New York: Sharpe.

Piercy, N., Kaleka, A., \& Katsikeas, C. (1998). Sources of competitive advantages in high performing exporting companies. Journal of World Business, 33(4), 378 393.

Porter, M. (1990). The Competitive Advantage of Nations. New York, NY: The Free Press.

Porter, M. (1998). The Competitive Advantage of Nations. New York, NY: The Free Press.

Ravichandran, T., \& Lertwongsatien, C. (2005). Effect of Information Systems Resources and Capabilities on Firm Performance: A Resource-Based Perspective. Journal of Management Information System, 21(4), 237-276.

Runyan, R. C., Huddleston, P., \& Swinney, J. L. (2007). A Resourced View of the Small Firm: Using a qualitative approach to uncover small firm resources. Qualitative Market Research: An International Journal, 10(4), 390-402.

Shamsuddoha, A. K., Ali, M. Y., \& Ndubisi, N. O. (2009). A conceptualisation of direct and indirect impact of export promotion programs on export performance of SMEs and entrepreneurial ventures. International Journal of Entrepreneurship, 13, 87-106. 
Tewari, M. (2005). Post-MFA adjustments in India's textile and apparel industry: emerging issuses and trends. Retrieved August 12, 2012, from http://papers.ssrn.com/sol3/papers.cfm?abstract_id=791885

Tewari, M. (2006). Adjustment in India's textile and apparel industry: reworking historical ;egacies in a post-MFA world. Environment and Planning, 38, 2325 2344.

Textile Intelligence. (2007, May 1). Foreign investment and collaboration in india's textile and apparel industry. Retrieved October 24, 2012, from Market Research.com: http://www.marketresearch.com/Textiles-Intelligencev2646/Foreign-Investment-Collaboration-India-Textile-1515576/

The Hindu. (2011). Court order on dyeing units' closure chokes Tirupur garment sector. Retrieved November 6, 2012, from The Hindu: Business Line: http://www.thehindubusinessline.com/industry-and-economy/article1153565.ece The Times of India. (2011, February 4). Relief for river pollution gets redistributed. Retrieved November 6, 2012, from The Times of India: http://articles.timesofindia.indiatimes.com/2011-0204/chennai/28358640_1_dyeing-units-noyyal-unit-and-effluent-treatment

USITC. (2001). India's textile and Clothing Industry: growth potential and trade and investment opportunities. Retrieved September 20, 2012, from United States International Trade Commision: http://hotdocs.usitc.gov/docs/pubs/research_working_papers/PUB3401.pdf Watchravesringkan, K., Karpova, E., Hodges, N., \& Copeland, R. (2010). The competitive position of Thailand's apparel industry: Challenges and opportunities 
for globalization. Journal of Fashion Marketing and Management, 14(4), 576597.

Wernerfelt, B. (1984). A resource based view of the firm. Strategic Management Journal, $5,171-180$.

World Trade Organization. (2012). World Trade Organization Statistical Database.

Retrieved 06 13, 2012, from

http://stat.wto.org/StatisticalProgram/WSDBViewData.aspx?Language=E 


\section{Appendix A}

In depth Interview Protocol 


\section{Interview Instrument}

\section{Basic Company Information}

1. Annual export sales

2. Years of operation

3. Main product category

4. Location

5. Infrastructure

6. Number of employees

\section{Demographic Information}

1. How long have you been with this company?

2. Please describe your current title and years in this position.

3. Please describe a position before the current title, if any.

\section{Key resources}

1. Please describe the strong points that your company has, relative to its major competitors.

2. What are your company's unique strengths that a competitor would find it hard to imitate? [Probe for details] What do you do to be different from your competitors?

3. How was your company able to obtain or build those strengths?

4. Please name three areas which you would like to enhance within your company? [Probe for details]

a. Why are those areas important for your company? 
5. What are three things that will guarantee to succeed in the apparel export industry? [Probe for details]

6. What are three things that will guarantee to fail in today's apparel export industry? [Probe for details]

\section{Ownership}

7. Please give a brief history of your company.

a. Probe whether it is joint venture, foreign, or domestic owner

8. How and when was your company founded?

9. How would you describe the growth path that your company has followed since its foundation?

\section{Demand conditions}

10. Who is your main buyer for your products (Buyers)?

11. What makes your company do business favorable to do business with them?

12. How do your foreign buyers help you develop certain skill sets or knowledge?

13. How do your foreign buyers not help you develop certain skill sets or knowledge?

\section{Supporting indusries}

14. What are the examples of your related industries other than the apparel, what industries affect your businesses the most?

15. How those industries help or deter your business? What are helpful? What are not?

b. How does this affect your business? 


\section{Government Policies/Supports}

16. What are your views of the government export support schemes?

17. What are the benefits of these government support schemes? What specific policy affects you organization the most? examples

18. What are the drawbacks of these government support schemes?

19. Do any of these affect the way you do your businesses? -from key resource perspectives. Explain...

\section{Chances}

20. Is there any knowledge or skills that you acquired without any intention or plans?

Probe

\section{General}

21. In your opinion where do you see the Indian apparel industry in future?

22. Are there any thoughts or opinions you would like to share? 


\section{APPENDIX B}

\section{Revised In depth Interview Protocol after Pilot Run}




\section{Interview Instrument}

\section{Basic Company Information}

1. Annual export sales

2. Years of operation

3. Main product category

4. Location

5. Infrastructure

6. Number of employees

\section{Demographic Information}

1. How long have you been with this company?

2. Please describe your current title and years in this position.

3. Please describe a position before the current title, if any.

\section{Key resources}

4. Please describe the strong points that your company has, relative to its major competitors.

5. What are your company's unique strengths that a competitor would find it hard to imitate? [Probe for details] What do you do to be different from your competitors?

6. How was your company able to obtain or build those strengths?

7. Please name three areas which you would like to enhance within your company? [Probe for details]

a. Why are those areas important for your company? 
8. What are three things that will guarantee to succeed in the apparel export industry? [Probe for details]

9. What are three things that will guarantee to fail in today's apparel export industry? [Probe for details]

\section{Ownership}

10. Please give a brief history of your company.

c. Probe whether it is joint venture, foreign, or domestic owner

11. How and when was your company founded?

12. How would you describe the growth path that your company has followed since its foundation?

\section{Demand conditions}

13. Who is your main buyer for your products (Buyers)?

14. What makes your company do business favorable to do business with them?

15. How do your foreign buyers help you develop certain skill sets or knowledge?

16. How do your foreign buyers not help you develop certain skill sets or knowledge?

\section{Supporting indusries}

17. What are the examples of your related industries other than the apparel, what industries affect your businesses the most?

18. How those industries help or deter your business? What are helpful? What are not?

d. How does this affect your business? 


\section{Government Policies/Supports}

19. What are your views of the government export support schemes?

20. What are the benefits of these government support schemes? What specific policy affects you organization the most? examples

21. What are the drawbacks of these government support schemes?

22. Do any of these affect the way you do your businesses? -from key resource perspectives . Explain...

\section{Chances}

23. Is there any knowledge or skills that you acquired without any intention or plans?

Probe

\section{General}

24. In your opinion where do you see the Indian apparel industry in future?

25. Are there any thoughts or opinions you would like to share? 
Appendix C

\section{Email Recruitment}


In am writing in regards to my thesis study. I am working towards my Masters at the University of Missouri in the Textile and Apparel Management. I am hoping you would be able to take part in this important study exploring the unique firm resources claimed by Indian apparel export firms. I know you would have great insight into this topic and would be honored if you would be willing to participate.

The study will involve a one and half hour interview regarding the key firm resources that your organization has in maintaining a competitive advantage in the market place. The interview will be arranged in a location of your convenience.

I am hoping you will be interested in taking part in the furthering of knowledge regarding the understanding of the Indian apparel export firms' key resources. 


\section{APPENDIX D}

\section{Oral Recruitment}




\section{Verbal Scripts for Recruitment}

My name is Debanjan Das and I am a second year Masters' student in the University of Missouri, USA. I am currently researching on the key firm resources possessed by the Indian apparel export firms and your assistance in participating in a one and half hour interview would be extremely valuable for this research. Your participation in this research is voluntary. Your privacy will be protected as all the information in the interview will be kept strictly confidential. If you have any questions concerning your rights as a participant, you may contact Campus Institutional Review Board at 573-8829585. If you have any questions regarding the research itself, you may contact me at 573529-7710 or by e-mail at ddmq3@ @issouri.edu. Thank you in advance for your assistance and time. 
APPENDIX E

Study Consent Form 
Project Title: Exploration of the unique firm resources claimed by Indian apparel export firms.

\section{Project Director: Debanjan Das}

\section{DESCRIPTION AND EXPLANATION OF PROCEDURES:}

The primary goal of this research is to investigate the actual resources possessed by the Indian apparel export firms. To address this goal, interview will be conducted which should take approximately 60 to 90 minutes

Your participation in this research is totally voluntary. If you agreed to be part of this study an audio recorded interview will be conducted. The subjects' names will not be linked to the audio interview to ensure privacy.

\section{CONFIDENTIALITY:}

Data will be saved anonymously and kept strictly confidential. Any electronic files will be saved with numeric codes, with no personal identifiers. Throughout the procedures, if you feel uncomfortable with any questions or experiences, you may stop participation at any time. Finally, only the researcher will have access to the data and the aggregated data will be analyzed and shared for publication to protect your confidentiality. The data will be kept for seven years after the study has been completed.

\section{RISKS AND DISCOMFORTS:}

It is anticipated that there are NO physical, psychological or sociological risks involved in participating in this study.

\section{BENEFITS TO SOCIETY:}

The results of this study will benefit society and industry by providing the specific knowledge about the resources unique to the Indian apparel industry. The results would 
also help students and future employees learn about the skills they need to sustain themselves in the apparel export industry.

\section{COMPENSATION/INCENTIVES:}

There is no direct compensation or incentive for your participation in this study.

\section{CONSENT:}

By signing this consent form, you agree that you understand the procedures and any risks and benefits involved in this research. You are free to refuse to participate or to withdraw your consent to participate in this research at any time without penalty or prejudice; your participation is entirely voluntary. Your privacy will be protected because you will not be identified by name as a participant in this project. Your privacy will be protected as all the information in your journals will be kept strictly confidential. If you have any questions concerning your rights as a participant, you may contact Campus Institutional Review Board at 001-573-882-9585. If you have any questions regarding the research itself, you may contact me at 001-573-529-7710 or by e-mail at ddmq3@mail.missouri.edu.

Thank you in advance for your assistance and time. By signing this form, you are agreeing to participate in the project described to you. Please keep this consent form with you for future references. 


\section{APPENDIX F}

Study Consent Form (in Hindi) 
एक मानव भागीदार के रूप में कार्य करने के लिए सहमति

परियोजना शीर्षक: अद्वितीय फर्म संसाधनों का विश्लेषण भारतीय परिधान निर्यात फर्मों के दावा किया है.

परियोजना निदेशक: Debanjan Das

प्रतिभागी का नाम:

\section{विवरण और प्रक्रियाओं की व्याख्या:}

इस शोध का प्राथमिक लक्ष्य के लिए वास्तविक भारतीय परिधान निर्यात फर्मों द्वारा पास संसाधनों की जांच करने के लिए है.इस लक्ष्य को संबोधित करने के लिए साक्षात्कार का आयोजन किया जा सकता है जो लगभग 60 से 90 मिनट लग चाहिए.

इस शोध में आपकी भागीदारी पूरी तरह स्वैच्छिक है. यदि आप इस अध्ययन का हिस्सा बनने पर सहमत हुए एक ऑडियो दर्ज साक्षात्कार आयोजित किया जाएगा. विषयों 'के नाम ऑडियो साक्षात्कार से लिंक नहीं किया गोपनीयता सुनिश्चित करेगा.

\section{गोपनीयता:}

डेटा गुमनाम और कड़ाई से गोपनीय रखा बचाया जाएगा. किसी भी इलेक्ट्रॉनिक फाइल अंकीय कोड से बचाया जाएगा, कोई व्यक्तिगत अभिज्ञापकों के साथ. प्रक्रियाओं के दौरान, यदि आप कोई प्रश्न या अनुभव के साथ असहज महसूस करते हैं, तो आप किसी भी समय भागीदारी को रोकने के हो सकता है. अंत में, केवल शोधकर्ता डेटा तक पहुँच है और एकत्रित डेटा और विश्लेषण किया जाएगा और अपनी गोपनीयता की रक्षा करने के लिए प्रकाशन के लिए साझा. डेटा सात साल के लिए रखा जाएगा के बाद अध्ययन पूरा कर लिया गया है.

\section{जोखिम और असुविधाएँ:}


यह अनुमान है कि वहाँ कोई भौतिक, मनोवैज्ञानिक या सामाजिक इस अध्ययन में भाग लेने में शामिल जोखिम भी हैं.

\section{समाज को लाभ:}

\section{मुआवजा / प्रोत्साहन:}

कोई प्रत्यक्ष या इस अध्ययन में अपनी भागीदारी के लिए मुआवजा प्रोत्साहन है.

\section{सहमति:}

इस सहमति पत्र पर हस्ताक्षर करके, आप इस बात से सहमत हैं कि आप प्रक्रिया और इस शोध में शामिल किसी भी जोखिम और लाभ को समझते हैं. आप करने के लिए भाग लेने के लिए या जुर्माना या पूर्वाग्रह के बिना किसी भी समय इस शोध में भाग लेने के लिए अपनी सहमति वापस लेने से मना करने के लिए स्वतंत्र हैं, आपकी भागीदारी पूरी तरह स्वैच्छिक है. क्योंकि आप नाम से इस परियोजना में एक भागीदार के रूप में नहीं की पहचान हो जाएगा आपकी गोपनीयता को संरक्षित किया जाएगा. आपकी गोपनीयता के रूप में अपनी पत्रिकाओं में सभी जानकारी को कड़ाई से गोपनीय रखा जाएगा संरक्षित किया जाएगा. यदि आप एक भागीदार के रूप में अपने अधिकारों के विषय में किसी भी सवाल है, तो आप 001-573-882-9585 में कैम्पस संस्थागत समीक्षा बोर्ड से संपर्क कर सकते हैं. यदि आप किसी भी अनुसंधान ही के बारे में प्रश्न है, तुम मुझे 001-573-5297710 या ddmq3@mail.missouri.edu पर ई - मेल के द्वारा संपर्क कर सकते हैं.

आपकी सहायता और समय के लिए अग्रिम में धन्यवाद. इस फॉर्म पर हस्ताक्षर करके, आप आप वर्णित परियोजना में भाग लेने के लिए सहमत हैं. भविष्य में संदर्भ के लिए आप के साथ इस सहमति - फार्म रखने.

\section{APPENDix G}

\section{Study Consent Form (in Tamil)}


மனித பங்கு செயல்பட ஏற்றுக்கொண்டாக

திட்ட தலைப்பு: தனிப்பட்ட நிறுவனம் ஆதாரங்களை பகுப்பாய்வு இந்திய ஆடை ஏற்றுமதி நிறுவனங்கள் கூறினார்.

திட்ட இயக்குனர்: Debanjan Das

பங்கேற்பாளர்கள் பெயர்:

\section{விவரம் மற்றும் நடைமுறைகள் பற்றிய விளக்கம்:}

இந்த ஆராய்ச்சி முதன்மை நோக்கம் இந்திய ஆடை ஏற்றுமதி நிறுவனங்கள் வசம் உண்மையான ஆதாரங்களை விசாரணை உள்ளது. இந்த இலக்கு முகவரி, பேட்டி சுமார் 60 முதல் 90 நிமிடங்கள் வேண்டும் நடத்தப்பட்டது

இந்த ஆராய்ச்சியில் உங்கள் பங்கு முற்றிலும் தன்னார்வ. இந்த ஆய்வின் ஒரு பகுதியாக இருக்க ஒப்பு என்றால் ஒரு ஆடியோ பதிவு பேட்டியில் நடத்தப்படும். பாடங்களை 'பெயர்கள் தனியுரிமை உறுதி ஆடியோ பேட்டி இணைக்கப்பட்ட முடியாது.

\section{ரகசியம்:}

தரவு அநாமதேயமாக மற்றும் கண்டிப்பாக பாதுகாப்பாக வைக்கப்பட்டு சேமிக்கப்படும். எந்த மின்னணு கோப்புகளை எந்த தனிப்பட்ட அடையாளங்களாக, எண் குறியீடுகள் கொண்ட சேமிக்கப்படும். ஏதேனும் கேள்விகள் அல்லது அனுபவங்களுடன் கஷ்டமாக இருந்தால், நடைமுறைகள் முழுவதும், நீங்கள் எந்த நேரத்திலும் பங்கு நிறுத்த வேண்டும். இறுதியாக, தான் ஆராய்ச்சியாளர் தரவு அணுகல் மற்றும் தொகுக்கப்பட்ட தரவு பகுப்பாய்வு மற்றும் உங்கள் ரகசியம் காக்க வெளியீட்டுக்கான 
பகிர்ந்து கொள்ளப்படும். ஆய்வு முடிந்த பிறகு தரவு ஏழு

ஆண்டுகளுக்கு வைக்கப்படும்.

\section{அபாயங்கள் மற்றும் உபாதைகள்:}

இந்த ஆய்வில் கலந்து தொடர்பு இல்லை உடல், உளவியல் அல்லது சமூகவியல் அபாயங்கள் உள்ளன என்று எதிர்பார்க்கப்பட்டது.

சமூகத்திற்கு நன்மைகள்:

\section{இழப்பீடு / ஊக்க தொகை:}

இந்த ஆய்வில் உங்கள் பங்கு எந்த நேரடி இழப்பீடு அல்லது ஊக்க உள்ளது.

\section{ஏற்றுக்கொண்டாக:}

இந்த ஒப்புதல் படிவத்தை கையெழுத்திட்டு, நீங்கள் நடைமுறைகள் மற்றும் இந்த ஆராய்ச்சியில் ஈடுபட்ட எந்த அபாயங்கள் மற்றும் பயன்களை புரிந்து என்பதை ஒப்புக்கொள்கிறேன். நீங்கள் பங்கேற்க அல்லது அபராதம் அல்லது பாரபட்சமும் இல்லாமல் எந்த நேரத்திலும் இந்த ஆராய்ச்சி பங்கேற்க உங்கள் அனுமதியின்றி திரும்ப பெற மறுப்பது இலவசம்; உங்கள் பங்கு முற்றிலும் தன்னார்வ. இந்த திட்டத்தின் ஒரு பங்கு என்ற பெயர் அடையாளம் முடியாது, ஏனெனில் உங்கள் தனியுரிமை பாதுகாக்கப்படும். உங்கள் பத்திரிகைகளில் அனைத்து தகவல் கண்டிப்பாக ரகசியமாக வைக்கப்படும் என உங்கள் தனியுரிமை பாதுகாக்கப்படும். நீங்கள் ஒரு பங்கு உங்கள் உரிமைகள் பற்றிய ஏதேனும் கேள்விகள் இருந்தால், நீங்கள் 001573-882-9585 உள்ள வளாகம் நிறுவன திறனாய்வு வாரியம் 
தொடர்பு இருக்கலாம். நீங்கள் ஆராய்ச்சி தன்னை பற்றி ஏதேனும் கேள்விகள் இருந்தால், நீங்கள் 001-573-529-7710 அல்லது ddmq3@mail.missouri.edu உள்ள மின்னஞ்சல் மூலம் என்னை தொடர்பு இருக்கலாம்.

உங்கள் உதவி மற்றும் நேரம் முன்கூட்டியே நன்றி. இந்த வடிவம் கையெழுத்திட்டு, நீங்கள் விவரித்தார் திட்டம் பங்கேற்க ஏற்கிறீர்கள். எதிர்கால குறிப்புகள் உங்களுக்கு இந்த ஒப்புதல் வடிவம் வையுங்கள். 


\section{APPENDIX H}

\section{Study Consent Form (in Kannada)}




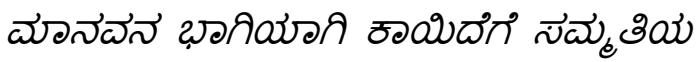

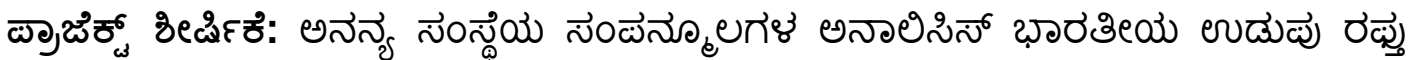
సెంत్థేగiళళ ळర్పు.

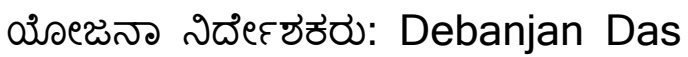

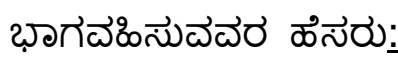

\section{దిదెరెణ దుత్తు ఏిధానేగిళ పిదరరెణ:}

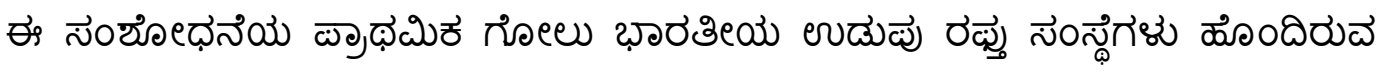

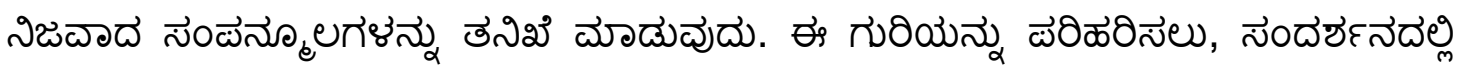

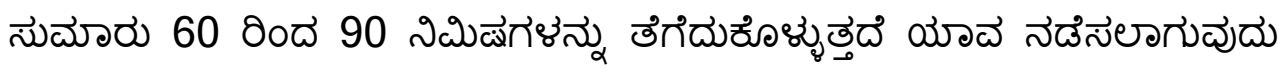

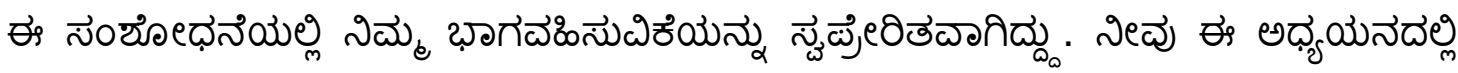

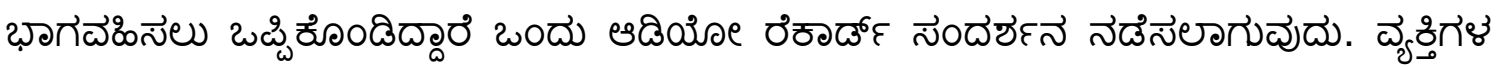

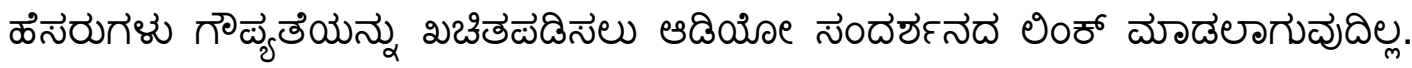

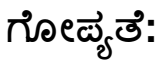

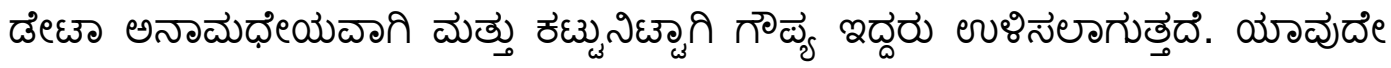

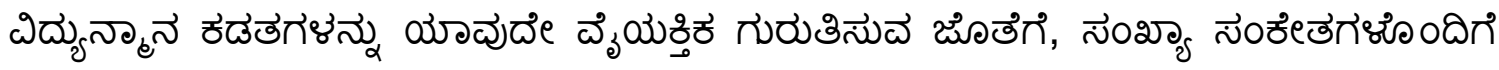

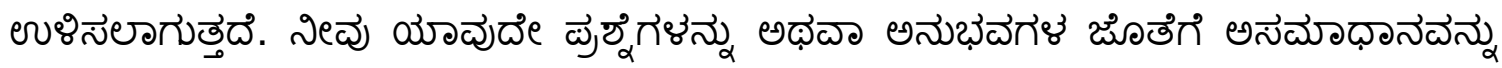

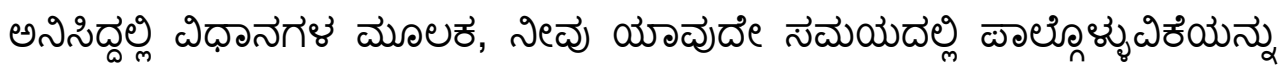

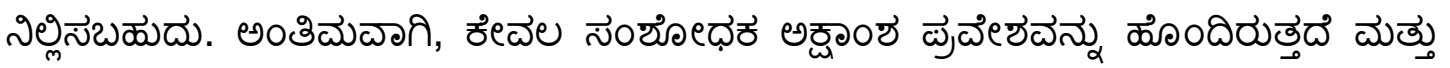

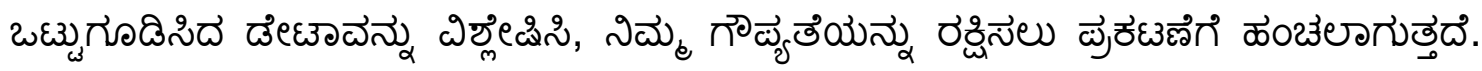

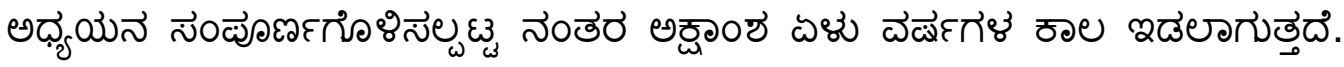

అळాయిగిళు దుత్తు అనానుశృలతైగిళు: 


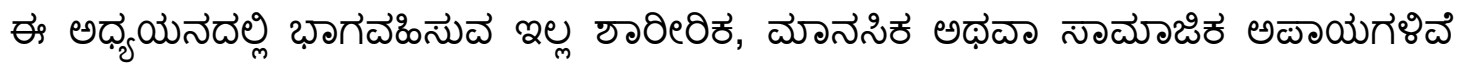
దందు నిరిలక్షిసెలాగిది.

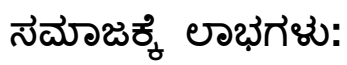

ఉరిదార / డేలెలత్సా:

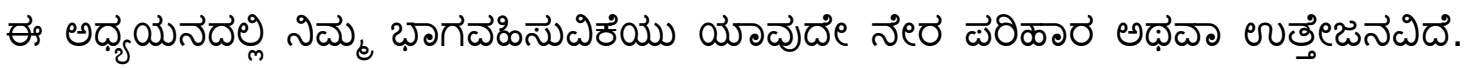
సెద్ముతియి:

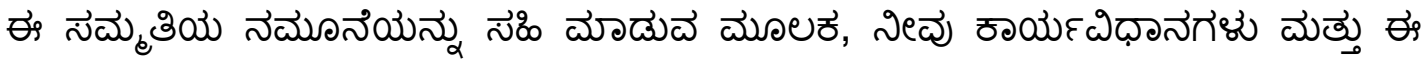

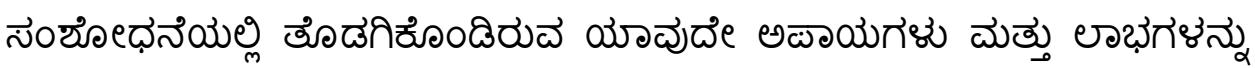

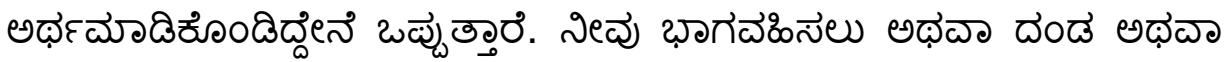

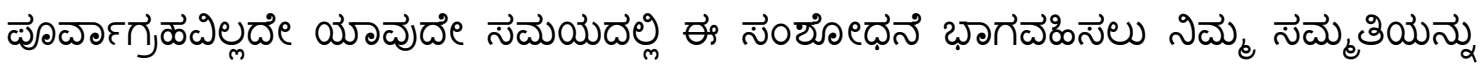

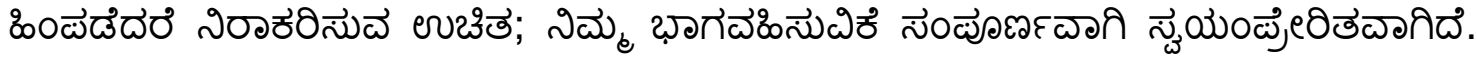

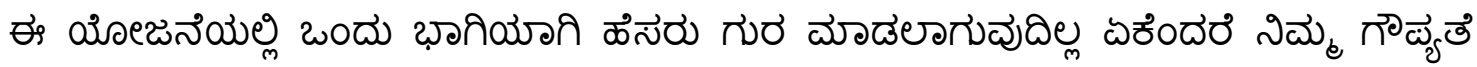

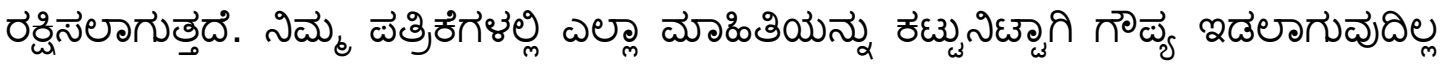

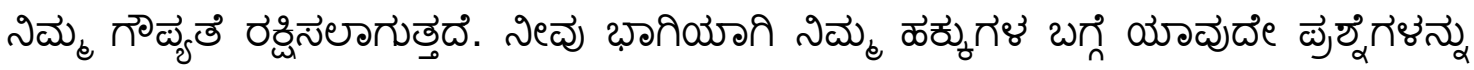

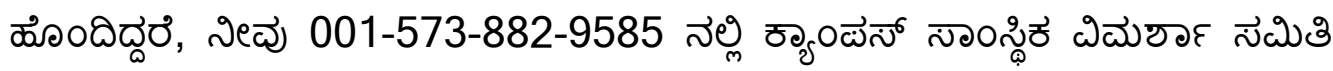

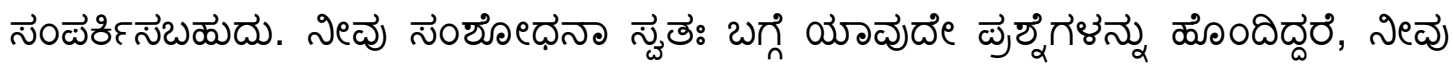
001-573-529-7710 అథळా ddmq3@mail.missouri.edu నెల్లి ఇదిలలో దొఠలక

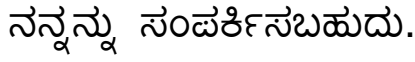

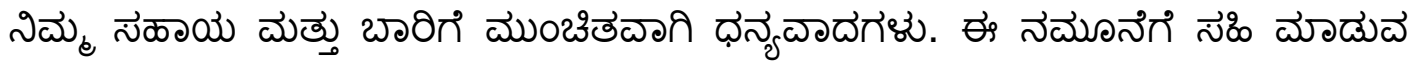

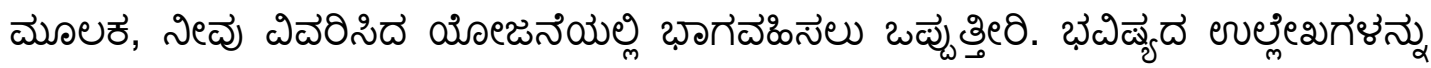

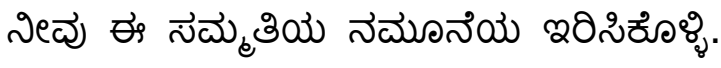




\section{APPENDIX I}

INSTITUTIONAL REVIEW BOARD APPROVAL FOR FINAL 
December 4, 2012

Principal Investigator: Das, Debanjan

Department: Textile and Apparel Mgmt

Your Application to project entitled EXPLORATION OF THE UNIQUE FIRM RESOURCES DESCRIBED BY INDIAN APPAREL EXPORT FIRMS FOR THEIR COMPETITIVE ADVANTAGES was reviewed and approved by the MU Campus Institutional Review Board according to terms and conditions described below:

\begin{tabular}{ll} 
IRB Project Number & 1205957 \\
Initial Application Approval Date & December 4, 2012 \\
IRB Expiration Date & December 4, 2013 \\
Level of Review & Exempt \\
Project Status & Active - Open to Enrollment \\
Regulation & 45 CFR 46.101b(2) \\
Risk Level & Minimal Risk \\
\hline
\end{tabular}

The principal investigator ( $\mathrm{PI}$ ) is responsible for all aspects and conduct of this study. The PI must comply with the following conditions of the approval:

1. No subjects may be involved in any study procedure prior to the IRB approval date or after the expiration date.

2. All unanticipated problems, serious adverse events, and deviations must be reported to the IRB within 5 days.

3. All modifications must be IRB approved by submitting the Exempt Amendment prior to implementation unless they are intended to reduce risk.

4. All recruitment materials and methods must be approved by the IRB prior to being used.

5. The Annual Exempt Form must be submitted to the IRB for review and approval at least 30 days prior to the project expiration date.

6. Maintain all research records for a period of seven years from the project completion date.

7. Utilize the IRB stamped document informing subjects of the research and other approved research documents located within the document storage section of elRB.

If you have any questions, please contact the Campus IRB at 573-882-9585 or umcresearchcirbemissouriedu.

Thank you,

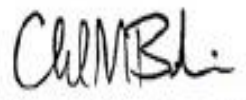

Charles Borduin, PhD

Campus IRB Chair 